Article

\title{
Development of a Universal Design-Based Guide for Handrails: An Empirical Study for Hong Kong Elderly
}

\author{
Vivian W. Y. Tam ${ }^{1, *(\mathbb{C}, \text { Ivan W. H. Fung }}{ }^{2}$, Y. T. Tsang ${ }^{2}$ and Leo Chan ${ }^{2}$ (]) \\ 1 School of Computing, Engineering and Mathematics Western Sydney University, \\ Australia and Honorary Professor, College of Civil Engineering, Shenzhen University, \\ Shenzhen 518060, China \\ 2 Department of Architecture and Civil Engineering, City University of Hong Kong, Kowloon Tong, \\ Hong Kong, China; ivan.fung@cityu.edu.hk (I.W.H.F.); yttsang@cityu.edu.hk (Y.T.T.); \\ leochanchikuen266@gmail.com (L.C.) \\ * Correspondence: vivianwytam@gmail.com; Tel.: +61-02-4736-0105
}

Received: 26 October 2018; Accepted: 13 November 2018; Published: 16 November 2018

check for updates

\begin{abstract}
An important and basic strategy for facilitating the inclusion and daily life of elderly in accordance with those living in public rental housing buildings is to allow their circulation to be barrier-free and self-supported. Therefore, the provision of a handrail guide could improve their living standard. This paper develops a universal design guide for handrails focusing on the needs of elderly. Fifteen routes with mostly elderly were selected and targeted for evaluating the existing problems with handrail provision. Surveys and informal interviews with elderly, adults, and children were also conducted to further investigate their needs, their ease of existing facilities, and possible future implementation to improve their ease. From the survey results, it was found that most of the existing problems with handrail layouts exist within the community. In addition to standardizing, modifying, and suggesting the ideas on handrail design and layout, the promotion of the ideas from universal design was the emphasis on this investigation in order to make a barrier-free city into a barrier-free but universal community for a better international city. The guide focuses on the standardization of synthetization of the scope in terms of design and layout. Simultaneously, an advanced part of design also regards the improvement of technological, environmental, and self-support features to improve Hong Kong's international friendliness with tailor-made ideas such as Elderlysteady.
\end{abstract}

Keywords: barrier-free handrail; risk-free handrail; universal design guide; elderly; Hong Kong

\section{Introduction}

Pursuing convenience and reasonableness, people always wish to utilize limited urban spaces; consequently, environments become complex and dense. Nevertheless, a fast-changing environment results in a gradually departure from the original picture of a city of elderly. To understand and get used to the environment, regulations, guides, or codes should be amended and improved according to physical characteristics and needs of the older generation around the world; otherwise, geniality would be lost along the way [1]. 
The elderly face increasing obstacles due to sensory changes, among others, due to age; in other words, the identity and abilities of the elderly cannot keep up with changes around their environment. In an age-friendly community, the environment is livable for the "white-haired" population; that is, the design, facilities, services, and policies support the lives of the older generation by enhancing affordability, health, safety, convenience, and quality of life [2]. A core value of an elderly-friendly community is respect for the lifestyle and decisions of aged people. At the same time, changing the role of the elderly from passive to active is also a major objective of age-friendly cities through the promotion of opportunities for older people to "live spontaneously" in a better way.

The World Health Organization [3] generally defines age-friendly cities based on three factors-outdoor spaces, buildings, and transportation-in the perspectives of design, facilities, services, and policies. Generally, a city that is age-friendly should provide diverse and elderly-friendly design, services, and facilities in a humanitarian way, for example, the separate provision of elevators and escalators that allow the elderly to have a chance for travel to another level corresponding to their physical ability. Commercial and governmental organizations are also responsible for enhancing the flexibility and affordability of the older generation. In regards to the general requirements for buildings and structural design specified by the World Health Organization [3], instead detailing the design of handrails, high accessibility is used to define additional barrier-free elements.

Nevertheless, handrails are undoubtedly fundamental fixtures that allow for grip in providing weight support and both psychological and physical stability to the elderly when walking, bending over, moving upward and downward, or even just standing [4]. Consequently, a tailor-made and well-assigned handrail systems along the circulation route within the public domain with respect to the elderly is necessary in an age-friendly community [5]. Handrails are necessary in an age-friendly community, as they solve problems associated with the elderly, such as common diseases, including osteoporosis, and disabilities [1]. Sometimes, handrails can act as a gadget for the elderly when intense physical effort is required. In modern design, handrails also serve as an anti-falling device to prevent any possible injuries [6]. Therefore, handrails are a necessity in a barrier-free city.

There is insufficient guidance or study about the provision of handrails among major daily access routes. This paper provides recommendations for a suitable provision of handrails to the passage route between existing public housing and the nearest train stations for the elderly at the local level, which allows a first step in the alternation and modification of existing handrails toward a practical age-friendly community. A guideline is developed herein for the provision of handrails based on the local situation of Hong Kong for the elderly. The core value is to provide a standardized guideline regarding the design code of handrails, including design (i.e., shape, material, color, diameter, distance from wall, load resistance, and additional requirements) and layout. Several suggestions are also provided in the framework of universal design [7], regarding handrails between the circulation route of public rental housing estates and the nearest train stations.

\section{Barrier-Free Handrail Design}

"Barrier-free" and "age-friendly" are closely related terms [8]. However, the idea of barrier-free is no longer fit for fast-changing environments, whereby the concept of universal design is gradually replacing it. Universal design is a barrier-free design that caters to various groups and communities.

Importantly, a standardization of handrail design regarding shapes, material, color, and height was provided by different codes and guidelines. The three most commonly adopted codes and guidelines are compared in "Aging in place guide for building owners: recommended age-friendly residential building upgrades" by the Department for the Aging, New York City [9]; "Design manual—barrier-free access" by the Buildings Department [10]; and "Universal accessibility—best practice and guidelines" by the Architectural Services Department [11] (see Table 1). 
Table 1. Comparison of codes and guidelines for handrails.

\begin{tabular}{|c|c|c|c|}
\hline Handrails Codes & $\begin{array}{c}\text { Department for the Aging, } \\
\text { New York City [9] }\end{array}$ & Buildings Department [10] & $\begin{array}{l}\text { Architectural Services } \\
\text { Department [11] }\end{array}$ \\
\hline Design & $\begin{array}{l}\text { Dual handrails; one high } \\
\text { (34-38 inches above the floor) } \\
\text { and one low (maximum } \\
27 \text { inches above the floor) }\end{array}$ & $\begin{array}{l}\text { Single handrail; no less than } \\
850 \mathrm{~mm} \text { and no more than } \\
950 \mathrm{~mm} \text { above the floor } \\
\text { Double handrail; no less than } \\
700 \mathrm{~mm} \text { and no more than } \\
800 \mathrm{~mm} \text { above the floor }\end{array}$ & $\begin{array}{l}\text { Single handrail; no less than } \\
850 \mathrm{~mm} \text { and no more than } \\
950 \mathrm{~mm} \text { above the floor }\end{array}$ \\
\hline Material & Slip-resistant surface & & \\
\hline Color & & $\begin{array}{l}\text { Minimum luminous contrast } \\
\text { of } 30 \% \text { with wall surfaces }\end{array}$ & Consistent in color \\
\hline \multirow[t]{2}{*}{ Diameter } & \multirow[t]{2}{*}{$1.25-2$ inches } & $\begin{array}{c}\text { No less than } 32 \mathrm{~mm} \text { and } \\
\text { no greater }\end{array}$ & \\
\hline & & than $50 \mathrm{~mm}$ & \\
\hline $\begin{array}{l}\text { Distance from } \\
\text { wall }\end{array}$ & 1 foot beyond the edge & $\begin{array}{l}\text { No less than } 30 \mathrm{~mm} \text { and no } \\
\text { more than } 50 \mathrm{~mm} \\
\text { No less than } 45 \mathrm{~mm} \text { for } \\
\text { rough-surfaced wall }\end{array}$ & \\
\hline Load resistance & & No less than $1.3 \mathrm{kN}$ & No less than $1.3 \mathrm{kN}$ \\
\hline $\begin{array}{l}\text { Additional } \\
\text { requirements }\end{array}$ & & & $\begin{array}{l}\text { Continuous handrail with } \\
\text { services along the corridor, } \\
\text { where a removable handrail is } \\
\text { required for opening }\end{array}$ \\
\hline
\end{tabular}

According to the Buildings Department [10], only three types of handrails are qualified under the code, named Types 1 to 3 (see Figure 1). However, only Type 1 was used throughout this guide for the sake of consistency.

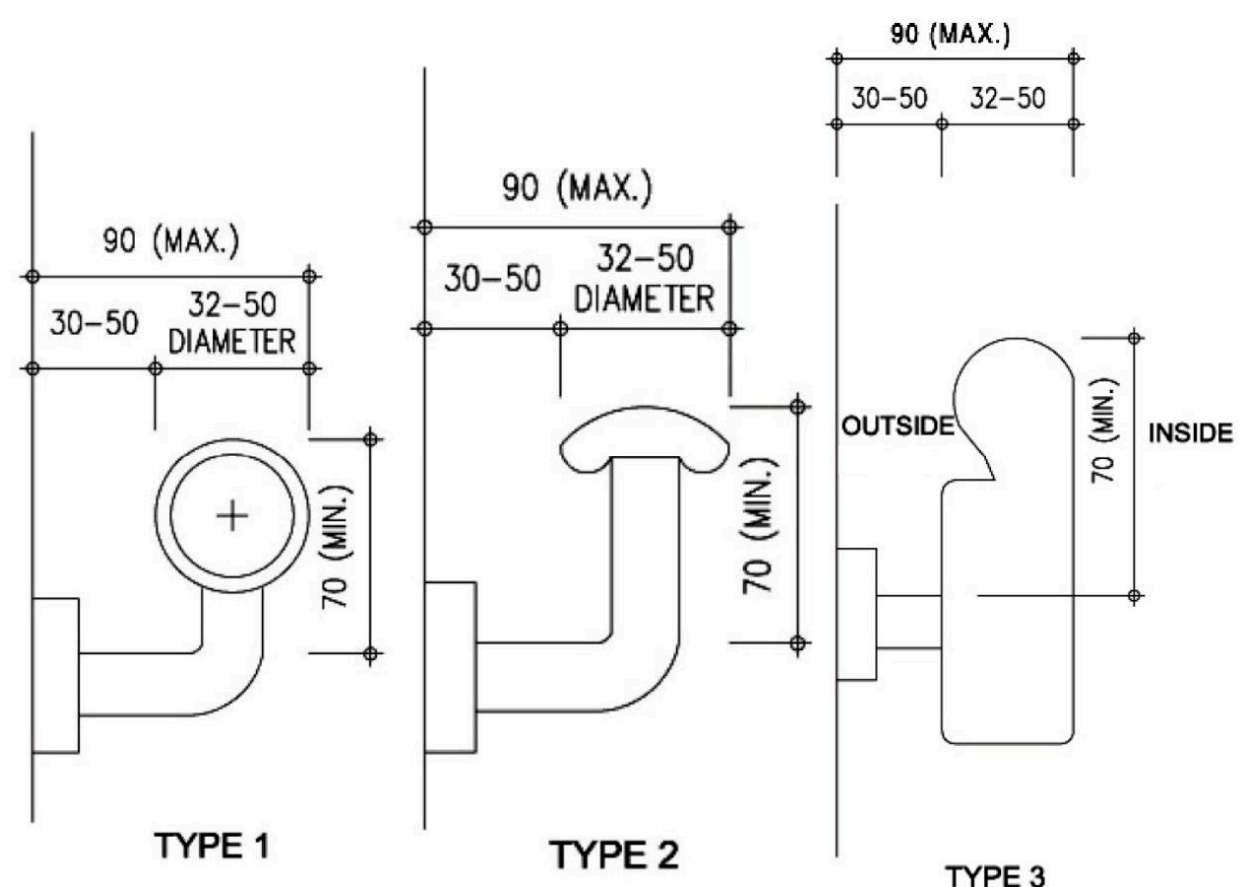

Figure 1. Three types of handrails specified under the framework by the Buildings Department. 
In addition to the default code, the design should also be fine-tuned according to the requirements of various implementers. According to the Mass Transit Railway (MTR) [12], red-colored handrail ends are provided for the staircase design to allow higher visibility for vision-impaired people, which should also be taken as an idea for the design of handrails to assist the elderly with visual difficulties (Figure 2).

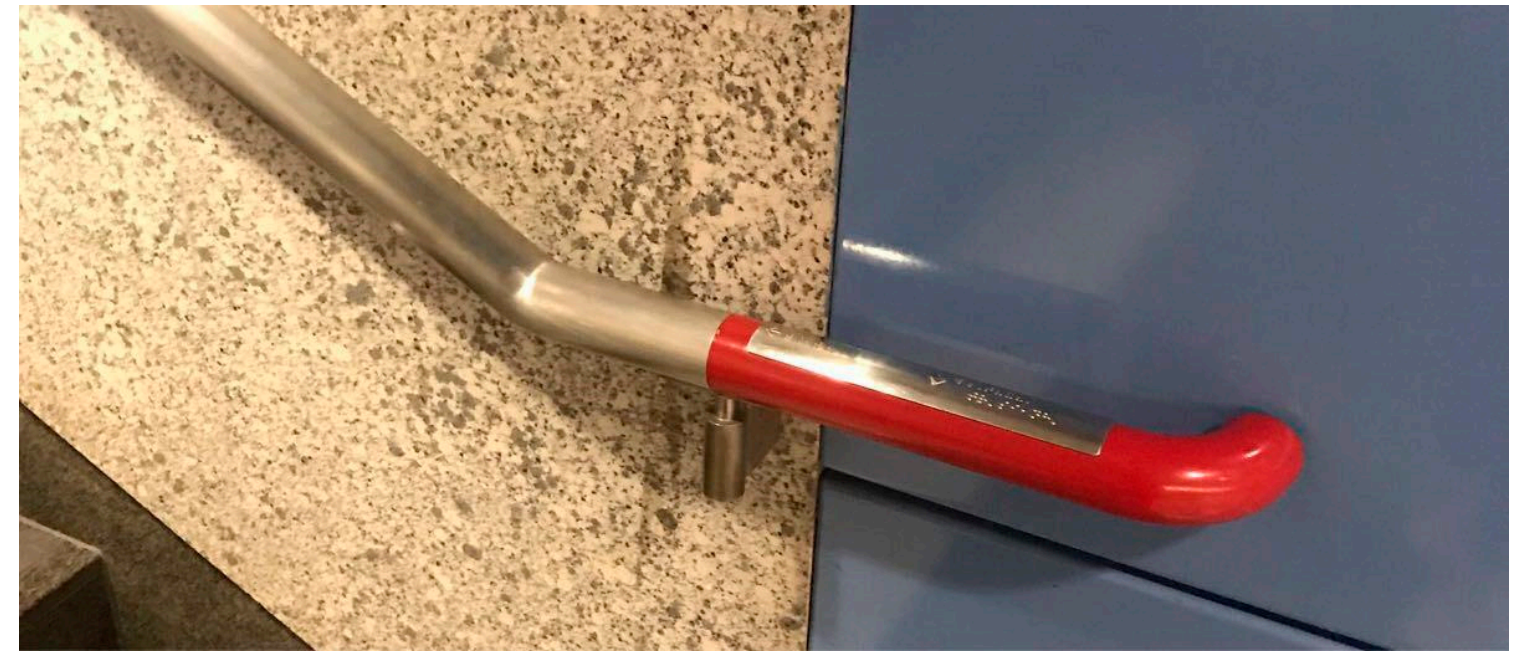

Figure 2. Red-colored handrail end photographed at the Olympic Mass Transit Railway (MTR) station.

Isabella and Rahel [13] mentioned that tactile guidance, small raised symbols, or notifiable changes in grip thickness should be provided, which could notify the breaks, as well as provide the directions of facilities, to blind or visually impaired people through braille messages inside the tactile symbols (Figure 3).

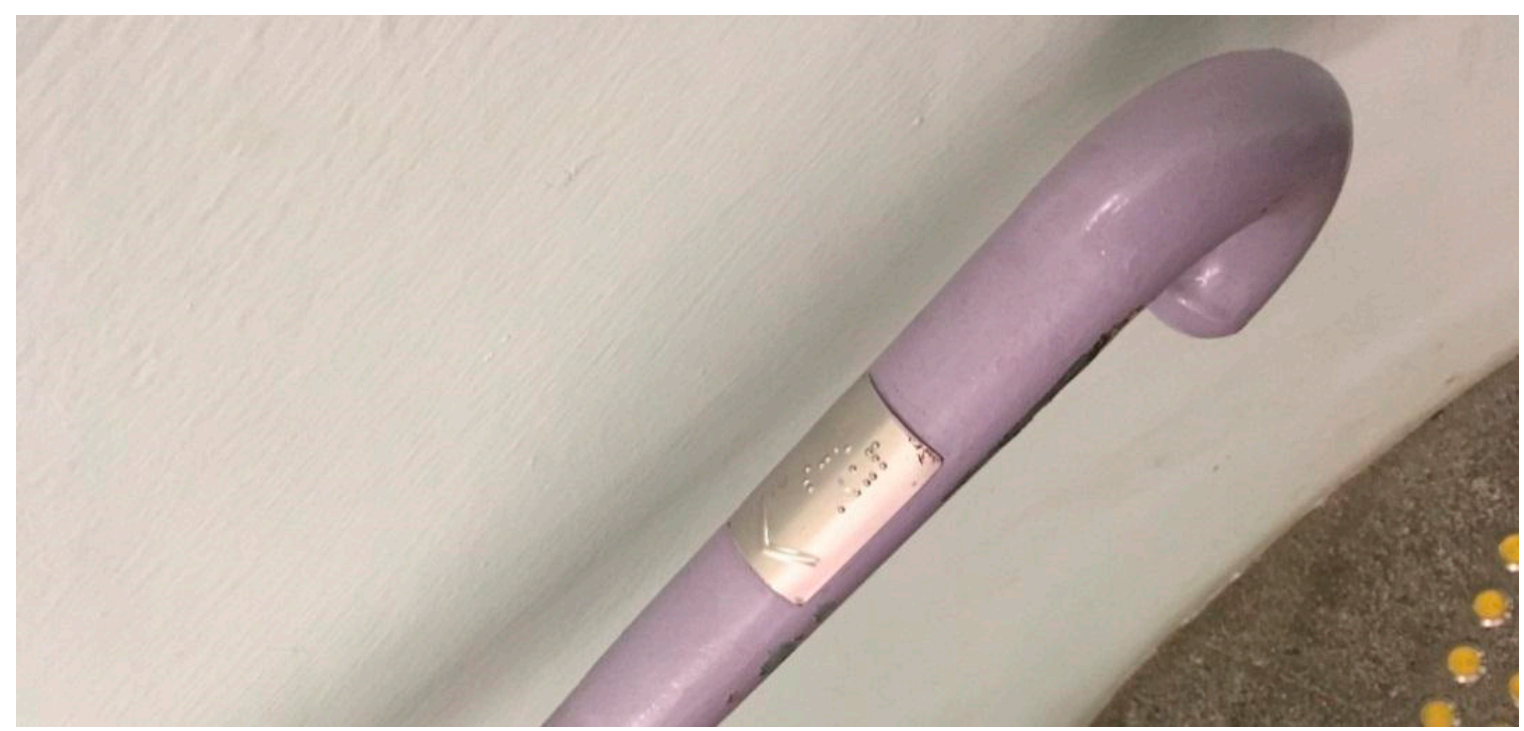

Figure 3. Braille sign photographed at the Ngau Tau Kok Municipal Services Building.

Unfortunately, the above braille sign design could only fundamentally provide the direction, without alleviating any safety concerns. Yanko Design [14] pointed out the design of a safety dot within an advanced braille sign, which could provide safety guidance (Figure 4). 

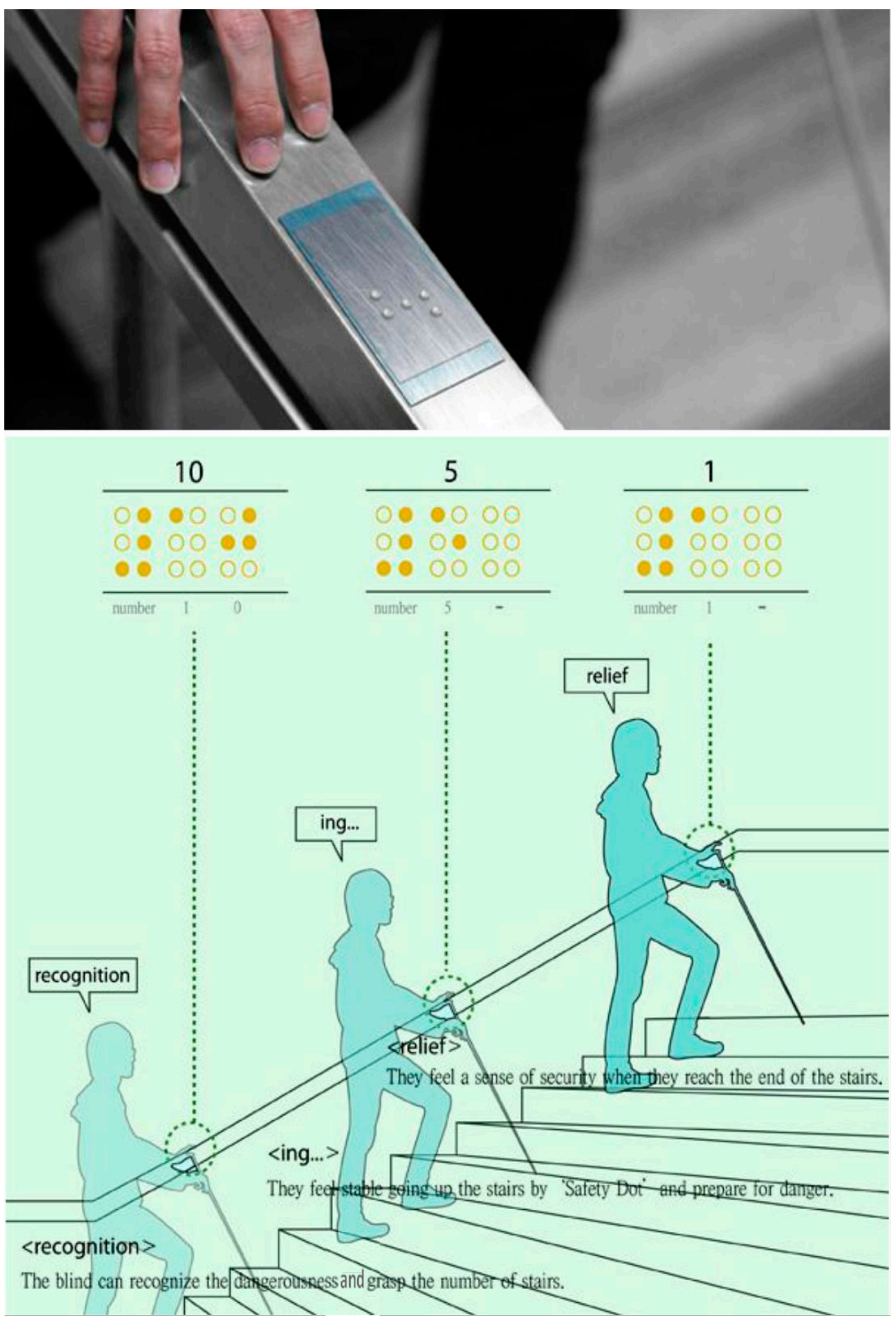

Figure 4. Safety dot idea from Yanko Design [14].

According to the Hong Kong Green Building Council [15], bamboo was applied in different fixtures or finishes, including handrails in the HSMC Jockey Club Residential Colleges for improving performance in the Building Environmental Assessment Method (BEAM) Plus (Figure 5). The Hong Kong Green Building Council [16] also mentioned that the selection of bamboo, which is a rapidly renewable raw material, was one of the assessment criteria. Obviously, the recommendation of bamboo materials could be provided for enhancing the green design of handrails. 
Handrails should be smooth and comfortable in grip with non-sharp edges and corners [17], which also establishes a flexible material design grid for handrails. Barker, Barrick, and Wilson [17] also pointed out that visually accentuated handrails could be very helpful for visually impaired people, and that forming a clear mental picture of a building and its surroundings is made much easier if there is a simple logical layout for the fixture.

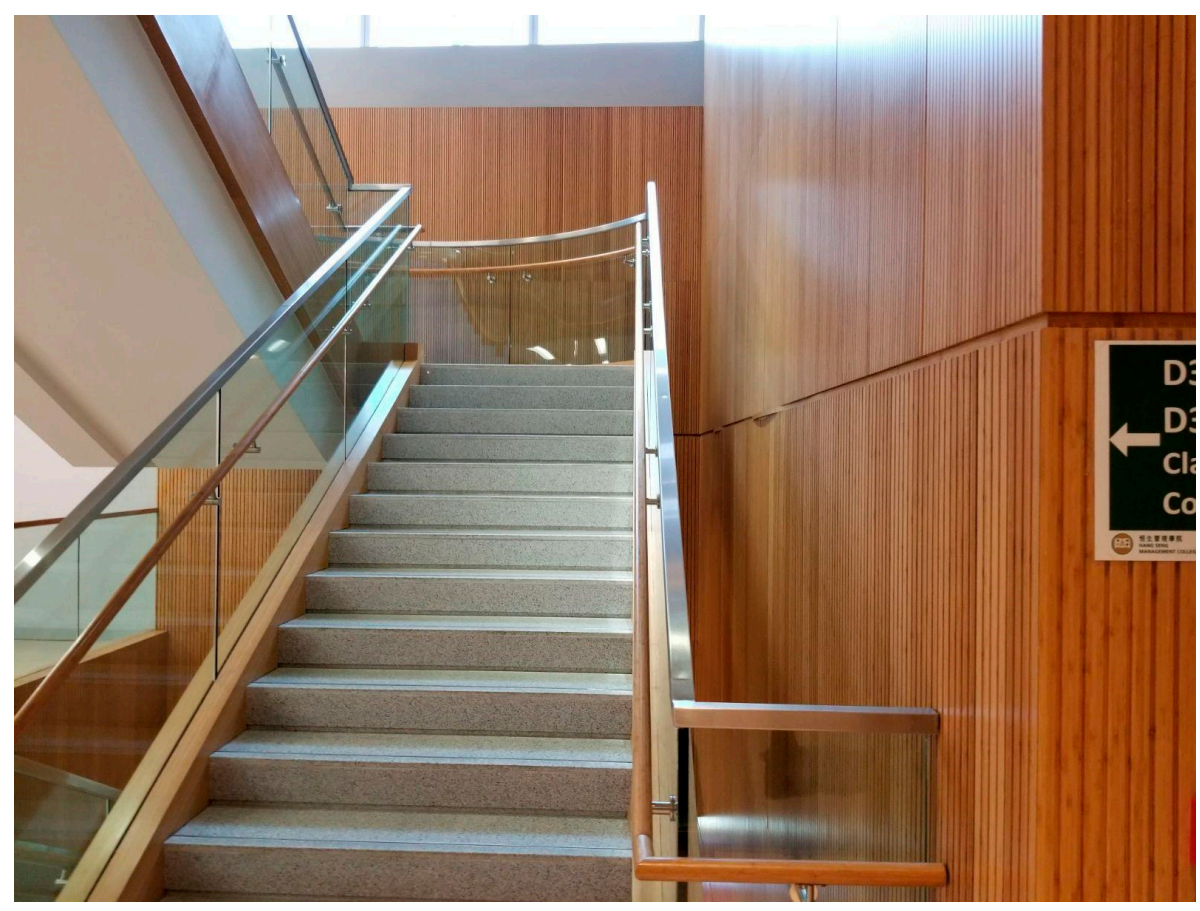

Figure 5. Bamboo handrails photographed at the HSMC Jockey Club Residential Building.

\section{Universal Design Handrails}

Naoto [18] pointed out that universal design is replacing barrier-free design, which allows catering to a wider group of people in a specific product design; therefore, to be age-friendly, the traditional approach should be eliminated. Seven principles are considered in universal design [19]: (1) equitable use; (2) flexibility in use; (3) simple and intuitive use; (4) perceptible information; (5) tolerance for error; (6) low physical effort; and (7) size and space for approach and use.

In real practice, these principles are not excluded in barrier-free design; however, they are only provided in certain areas, spaces, and facilities, such as welfare facilities and shopping malls. As a result, the major value of universal design is the merging of barrier-free design into all daily life environments. Simultaneously, pursuing diverse performance to suit different individual needs and preferences is essential for eliminating any obstacles to certain groups and communities.

Nevertheless, the achievement of comfort and safety in the universal design framework is extremely difficult. In fact, if it is written into regulations or codes, flexibility and creativity are eliminated. Consequently, standardization for the design and provision of handrails could facilitate the meeting of requirements, which is one of the goals of creating this guideline.

There are different universal design guides available. The most commonly adopted is the Universal Design Style, the requirements of which are summarized in Table 2. Table 3 compares the code from Hong Kong and the Universal Design Style. Codes for handrail design from Hong Kong are sufficiently comprehensive; however, certain elements mentioned in the Universal Design Guide are not covered. Therefore, the Universal Design Guide was used as a basis, while some of the design details (e.g., the height of the handrails) followed the Hong Kong code. These details were chosen following precise experiments using Hong Kong citizens, while considering the value of universal usage. 
Table 2. Summary of the Universal Design Style standard on handrails [20].

\begin{tabular}{ll}
\hline & Handrails should be provided for raised floor ramps that are more than $150 \mathrm{~mm}$. \\
& Handrails should be placed at a height such that the top is no less than $865 \mathrm{~mm}$ and no more than $965 \mathrm{~mm}$ \\
above the floor level. & Handrails designed for children should be placed at a height such that the top is no more than $710 \mathrm{~mm}$, \\
General & Hith a minimum distance of $230 \mathrm{~mm}$ from the upper handrails. \\
& Handrails should not be required surfaces with a slope lower than 1:20. \\
& Handrails are not required to be installed on both sides of travel in assembly areas. \\
& A minimum distance of $38 \mathrm{~mm}$ from the wall is required for the gripping surface. \\
\hline Gripping Surface & $\begin{array}{l}\text { Handrails should be provided on a continuous basis, i.e., continuous throughout the full length of passage } \\
\text { expect for assembly areas with unobstructed gripping surfaces, where more than } 20 \% \text { of its length is } \\
\text { obstructed; otherwise, a horizontal projection should be provided below the bottom gripping surface at a } \\
\text { minimum distance of } 38 \text { mm, except for handrails provided for surfaces with a slope lower than } 1: 20 .\end{array}$ \\
\hline Extension & $\begin{array}{l}\text { Non-circular designs should have a perimeter that no less than } 100 \text { mm and no more than } 160 \text { mm. } \\
\text { Instead of sharp-edged or abrasive surfaces, round-edged surfaces should be provided. }\end{array}$ \\
Handrails for ramps should be extended above the surface by at least 305 mm horizontally in a continuous \\
manner, for the top and bottom of the ramp. \\
Bottom extension: handrails for stairs should be extended along the slope, where the extension length should \\
be at least equal to the tread depth and reconnected to the adjacent surface in a continuous manner. Top \\
extension: handrails for stairs should be extended above the surface by at least 305 mm horizontally in a \\
continuous manner.
\end{tabular}

Table 3. Comparison between Hong Kong code and Universal Design Style guide.

\begin{tabular}{ccc}
\hline & Hong Kong Code & Universal Design Style \\
\hline Height & $\checkmark$ & $\sim$ \\
Material & $\sim$ & $\checkmark$ \\
Load resistance & $\checkmark$ & $\checkmark$ \\
Cross-section & $\checkmark$ & $\checkmark$ \\
Distance from wall & $\checkmark$ & $\sim$ \\
Color & $\sim$ & $\checkmark$ \\
Shape & $\checkmark$ & $\sim$ \\
Extension & $\checkmark$ & $\checkmark$ \\
Continuity & $\sim$ & $\checkmark$ \\
Ramps & $\checkmark$ & $\checkmark$ \\
Gripping surface & $x$ & $\sim$ \\
Barrier railing & $x$ &
\end{tabular}

$\checkmark$-Mentioned in detail; $\sim$-mentioned but not in detail; $\boldsymbol{x}$ —not mentioned.

\section{Research Methodology}

To achieve the aim of this paper in developing a universal design-based guide with barrier-free ideas for the provision of handrails targeting the needs of the elderly living in public rental flats, two main issues were investigated: (1) to develop a standardized and fine-tuned design based on the Universal Design Style code of handrails regarding design, shape, material, color, diameter, distance from wall, load resistance, additional requirements, and layouts with advanced and tailor-made ideas; and (2) to make suggestion for handrails in between circulation routes of public rental housing estates and the nearest MTR stations in terms of their layout.

Survey and field studies were carried out to discover any existing problems or deficiencies of current handrails provided on the designated route, evaluated by Google Maps. An assumption was made that the elderly would choose to travel via MTR when the routes toward the nearest MTR stations from their public rental flat requiring no less than $10 \mathrm{~min}$ travel on foot. Therefore, a simple online instrument, Google Maps, was used to evaluate target routes that required a travel time no less than $10 \mathrm{~min}$ on foot. Fifteen routes with mostly elderly were selected as references to generate and represent the existing problems with handrails. Figures 6-20 summarize the within-10-min walking routes between public rental housing estates and the nearest MRT stations. 


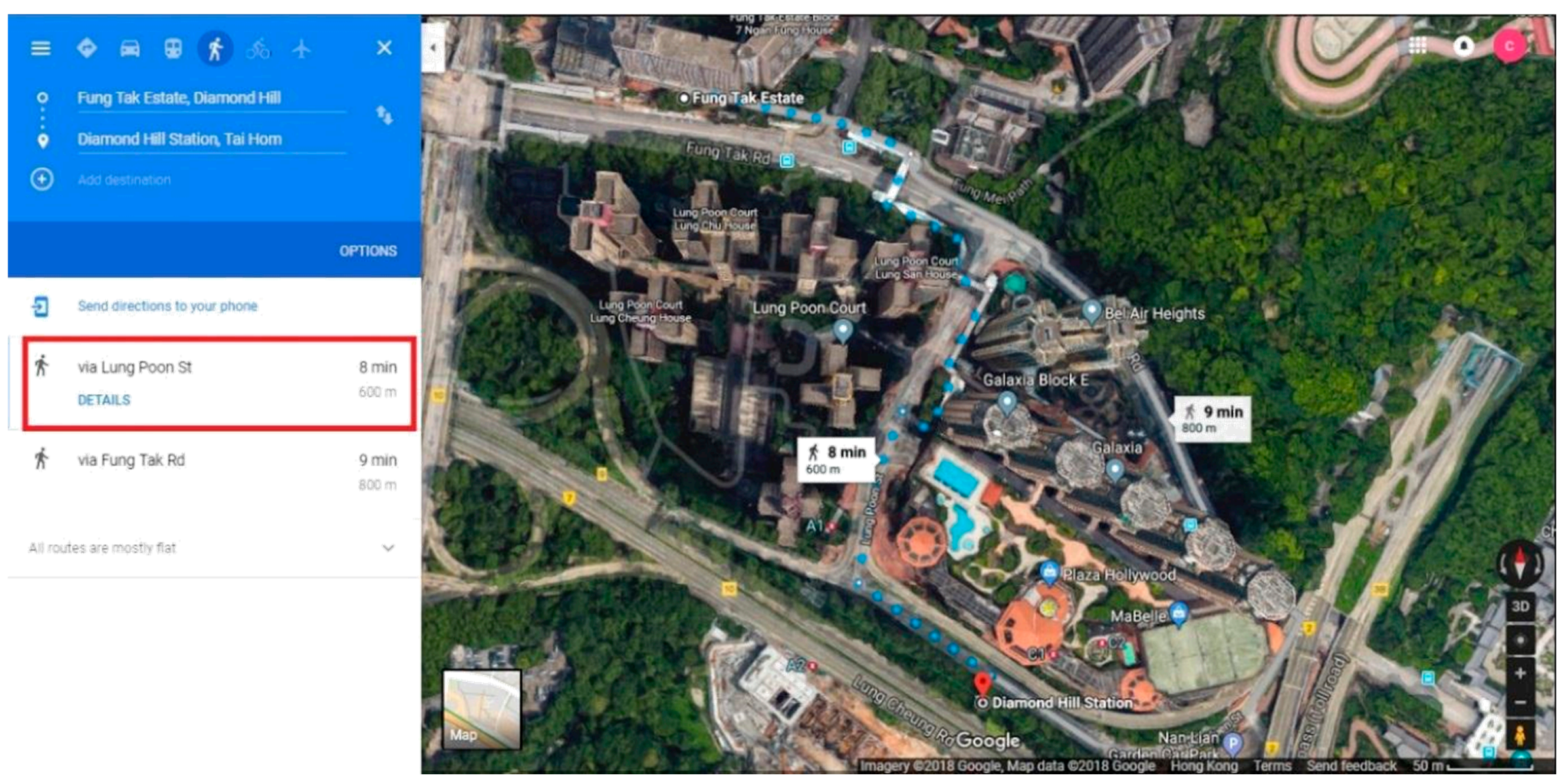

Figure 6. Walking route between Tai Hung Tung Estate and the Shek Kip Mei MTR station. 


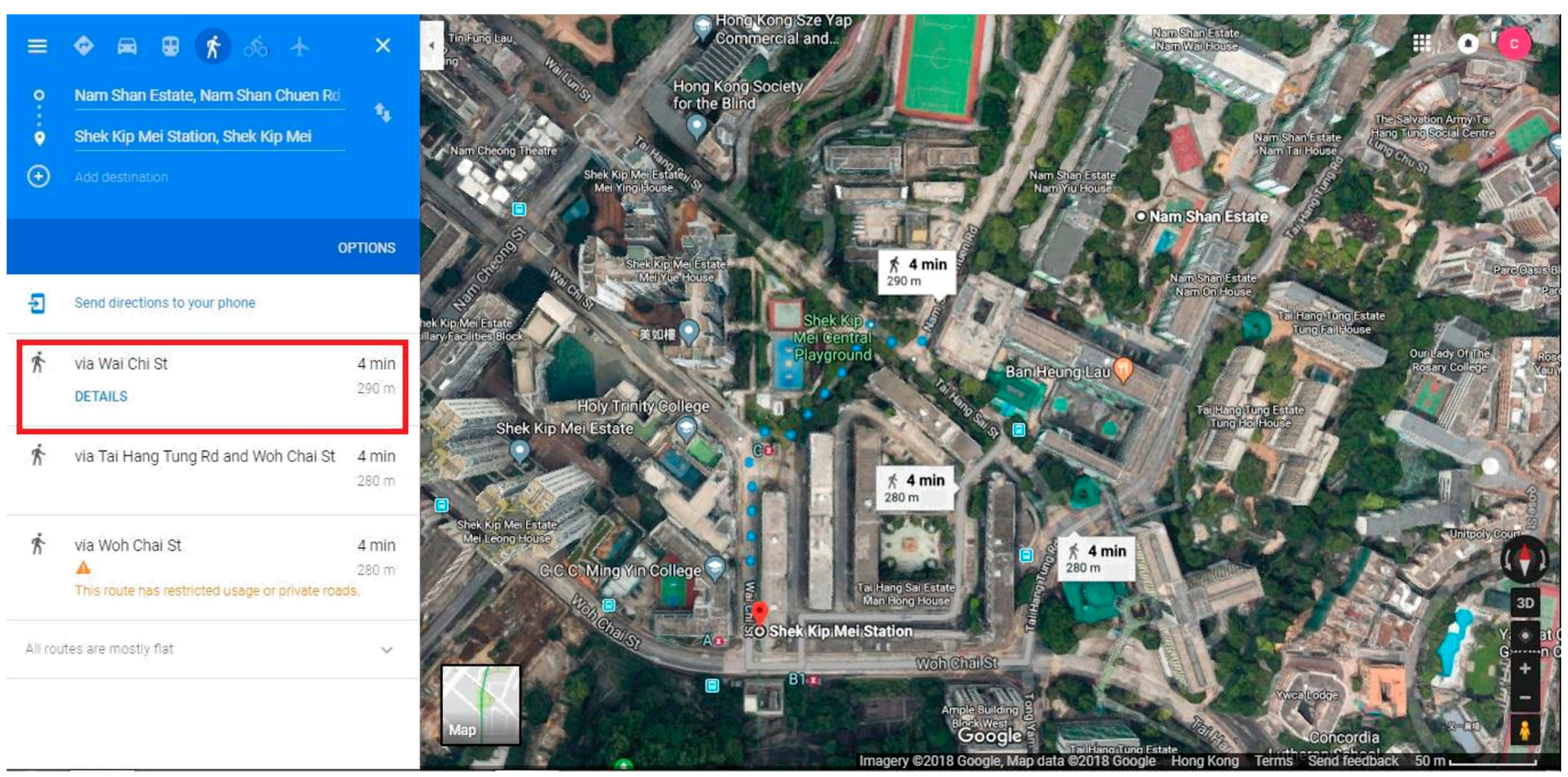

Figure 7. Walking route between Nam Shan Estate and the Shek Kip Mei MTR station. 


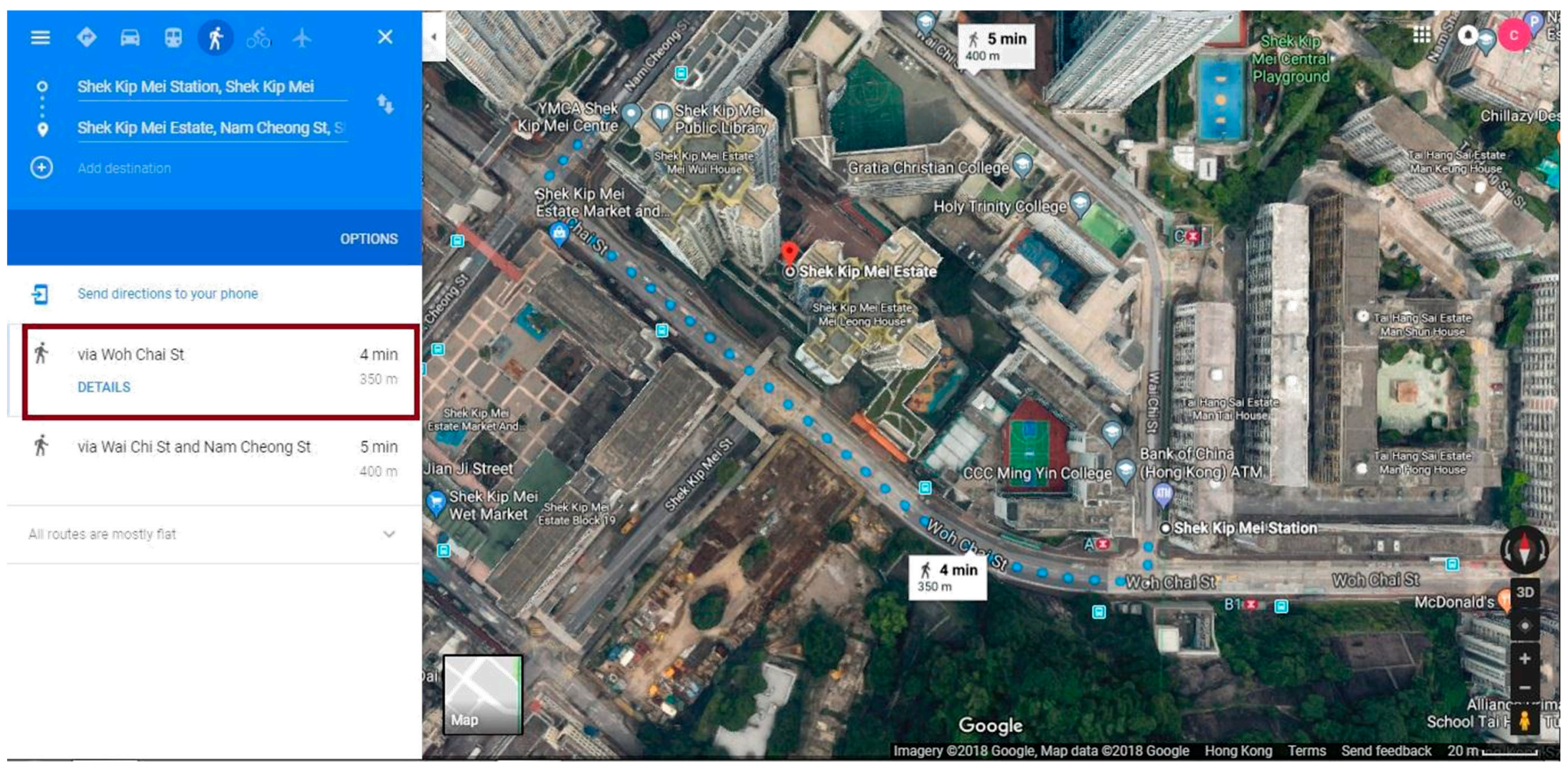

Figure 8. Walking route between Shek Kip Mei Estate and the Shek Kip Mei MTR station. 


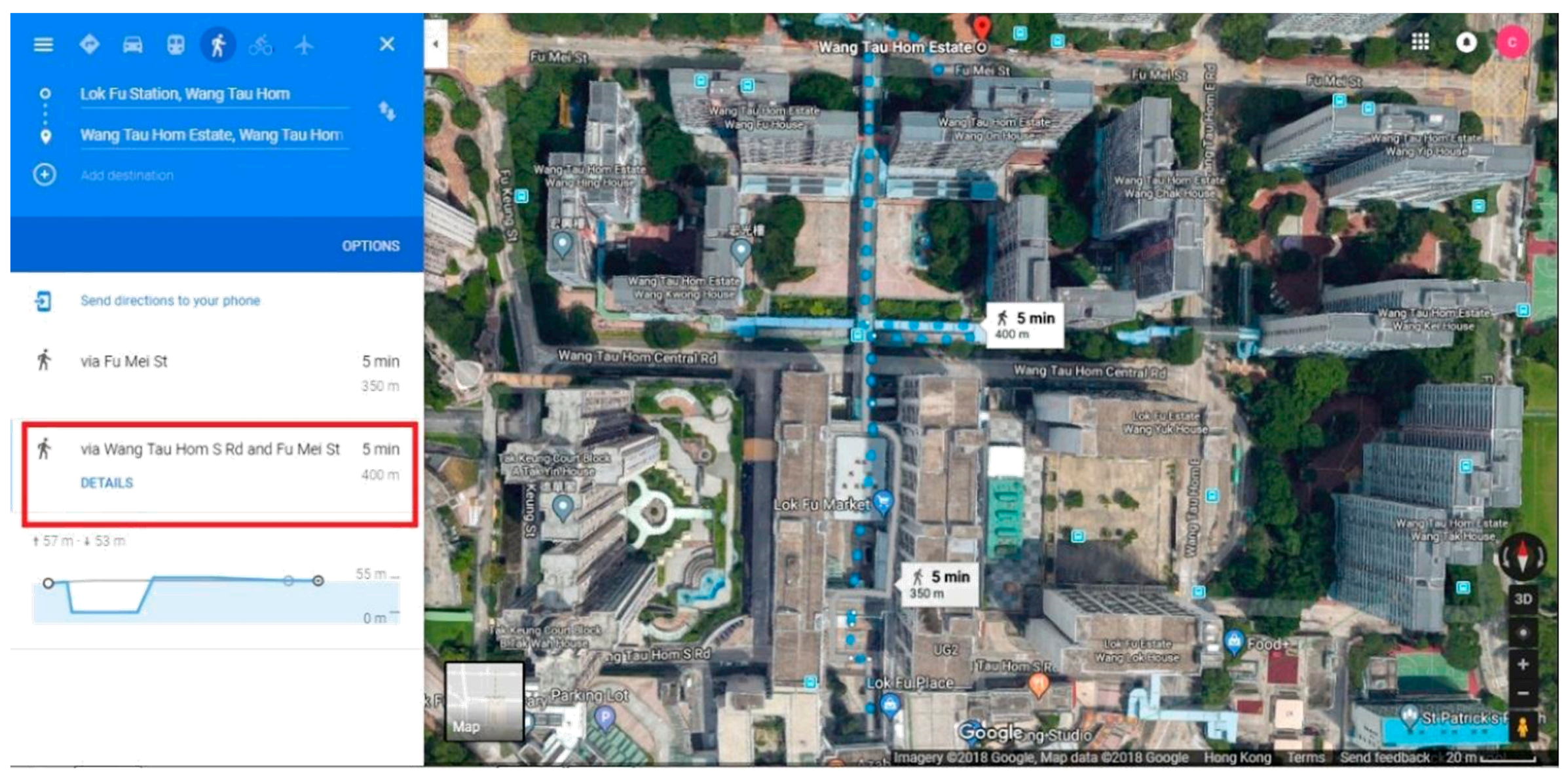

Figure 9. Walking route between Wang Tau Hom Estate and the Lok Fu MTR station. 


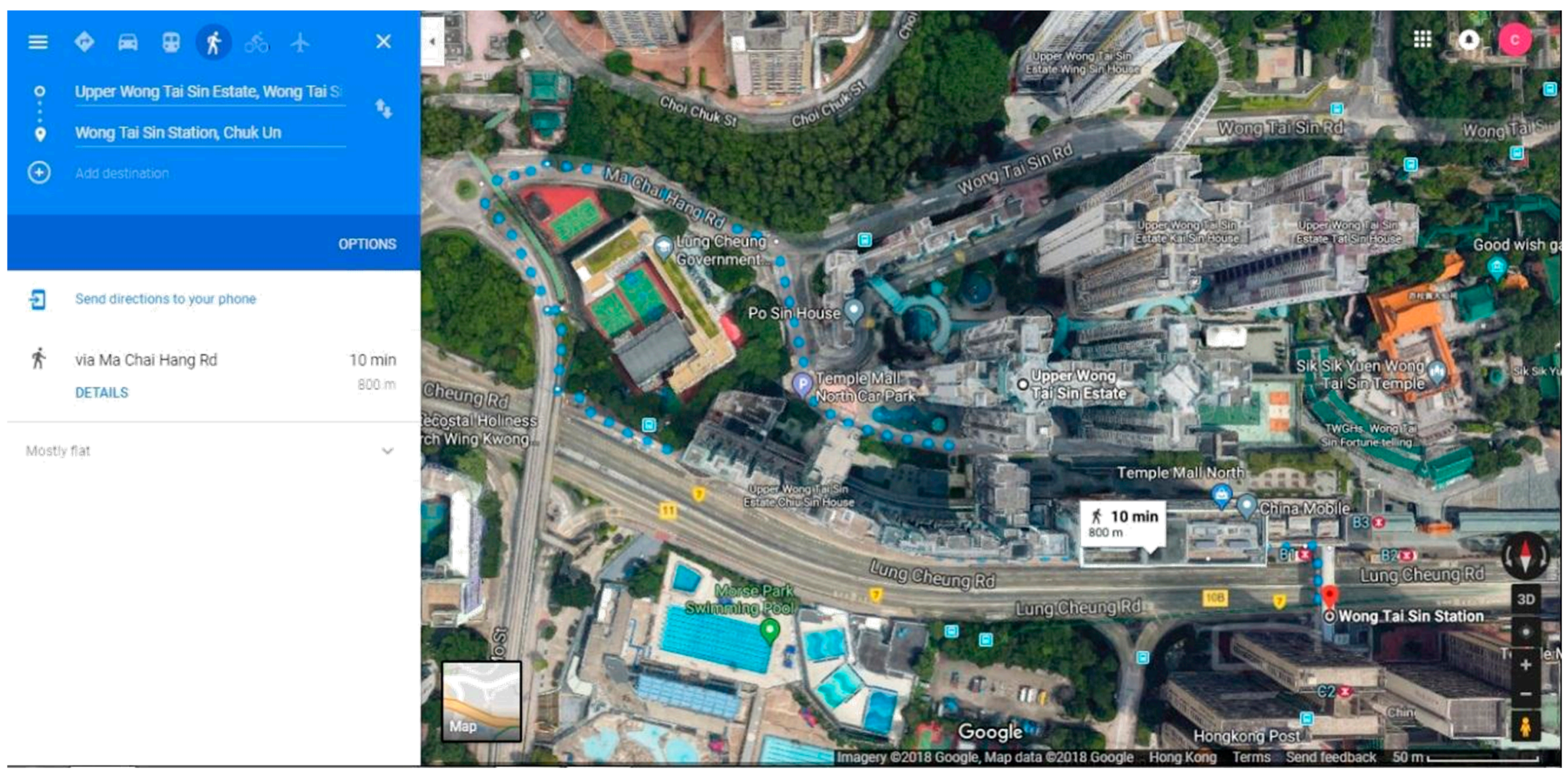

Figure 10. Walking route between Upper Wong Tai Sin Estate and the Wong Tai Sin MTR station. 


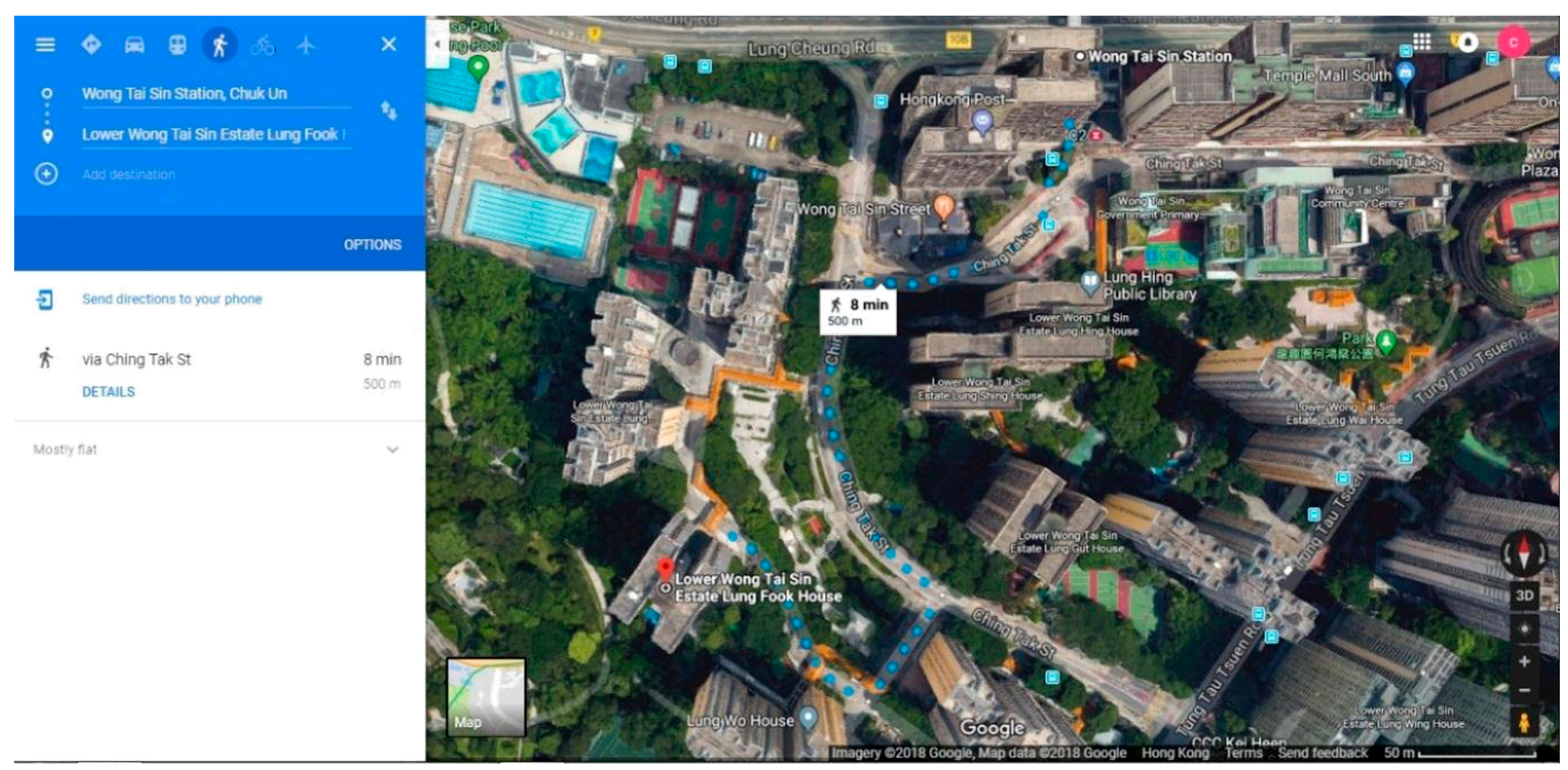

Figure 11. Walking route between Lower Wong Tai Sin Estate and the Wong Tai Sin MTR station. 


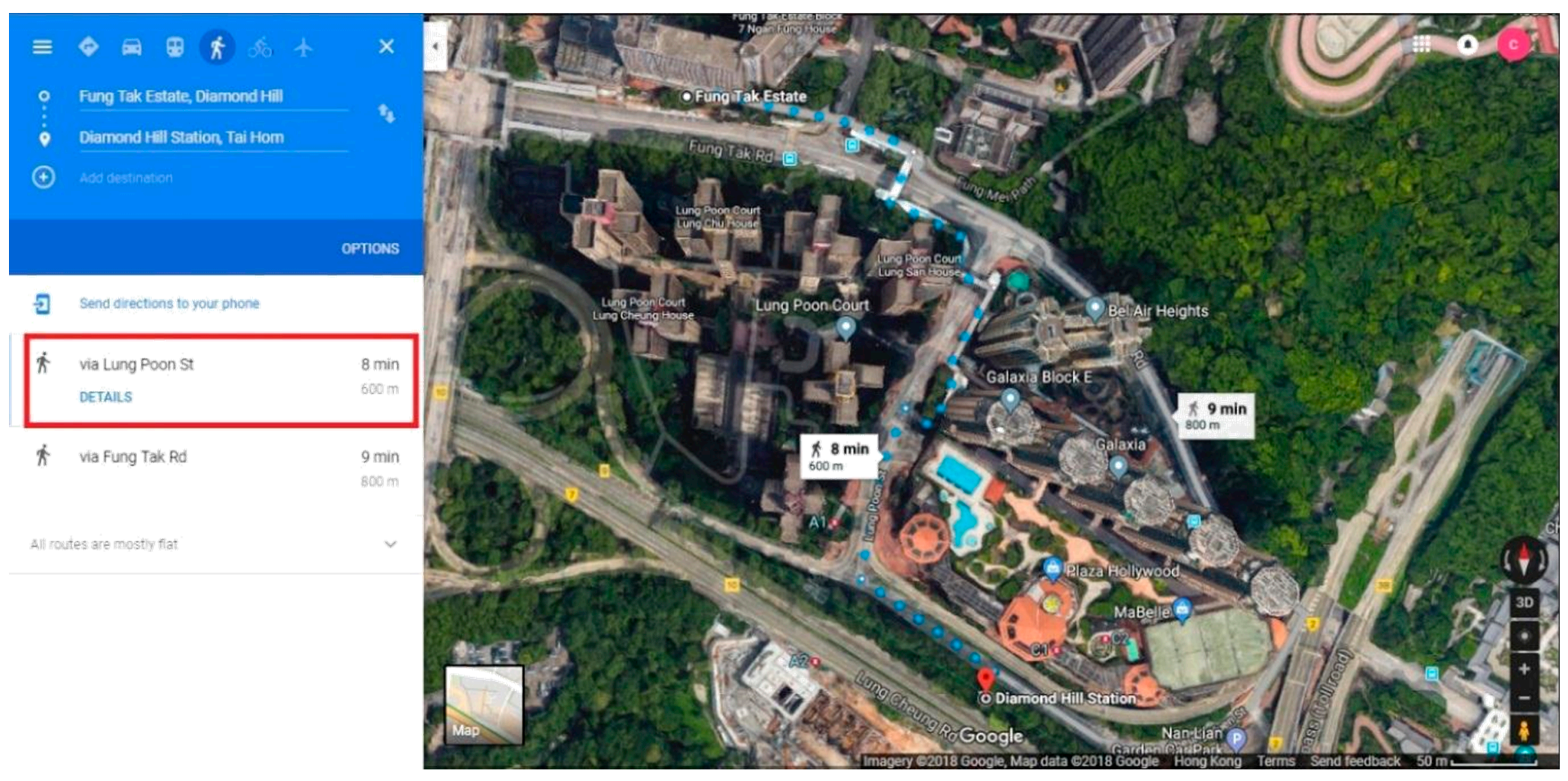

Figure 12. Walking route between Fung Tak Estate and the Diamond Hill MTR station. 


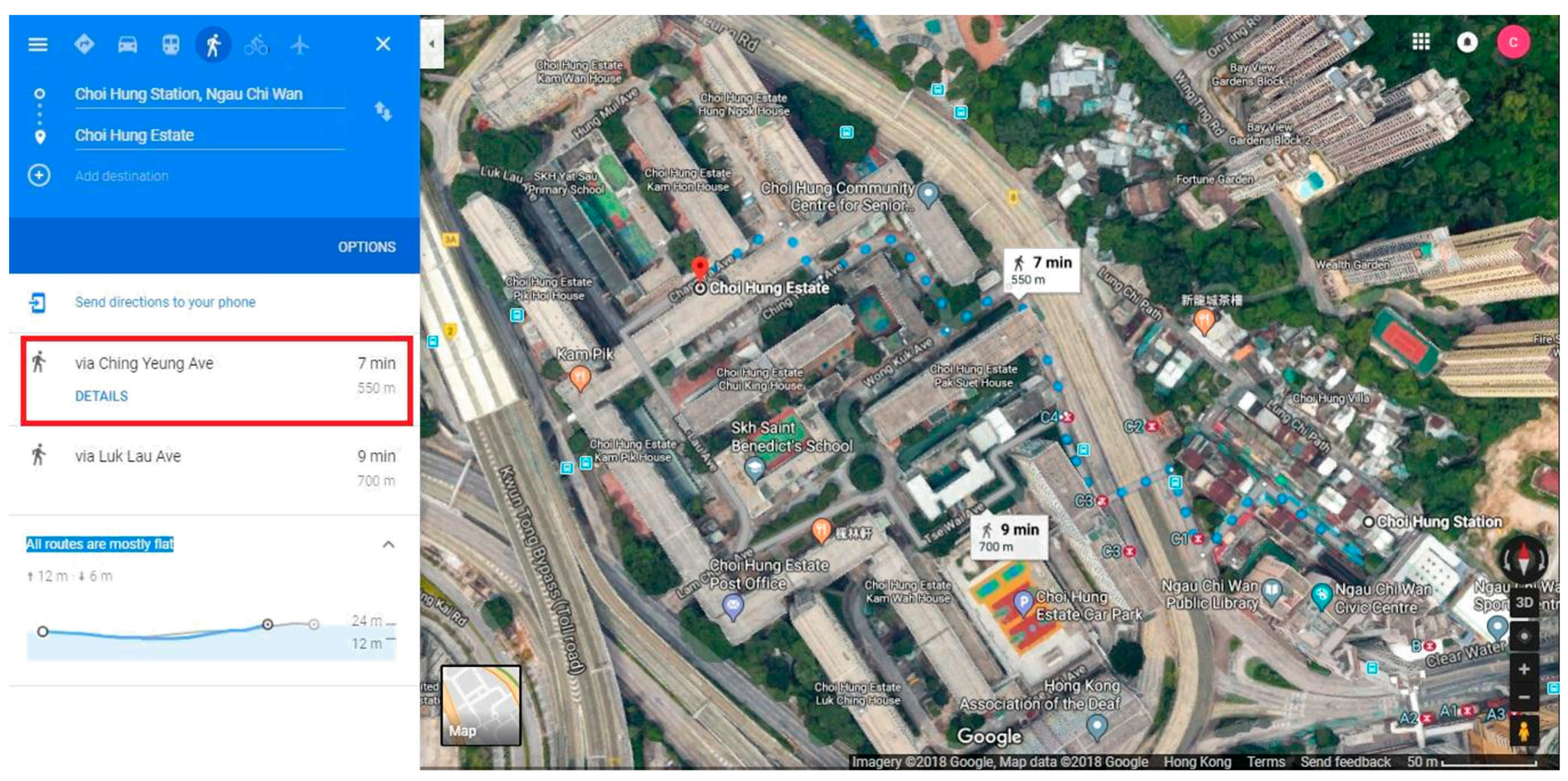

Figure 13. Walking route between Choi Hung Estate and the Choi Hung MTR station. 


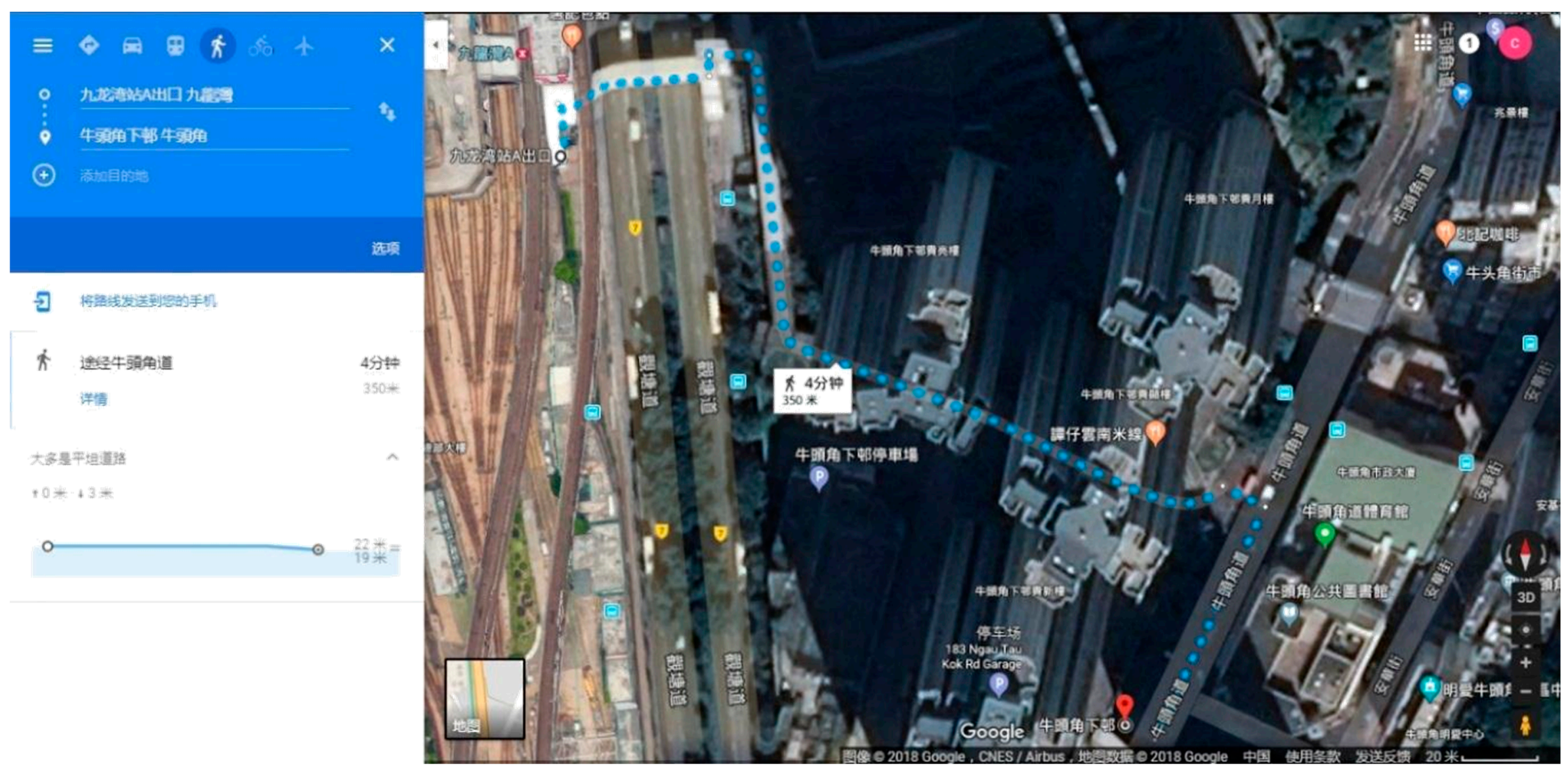

Figure 14. Walking route between Lower Ngau Tau Kok Estate and the Ngau Tau Kok MTR station. 


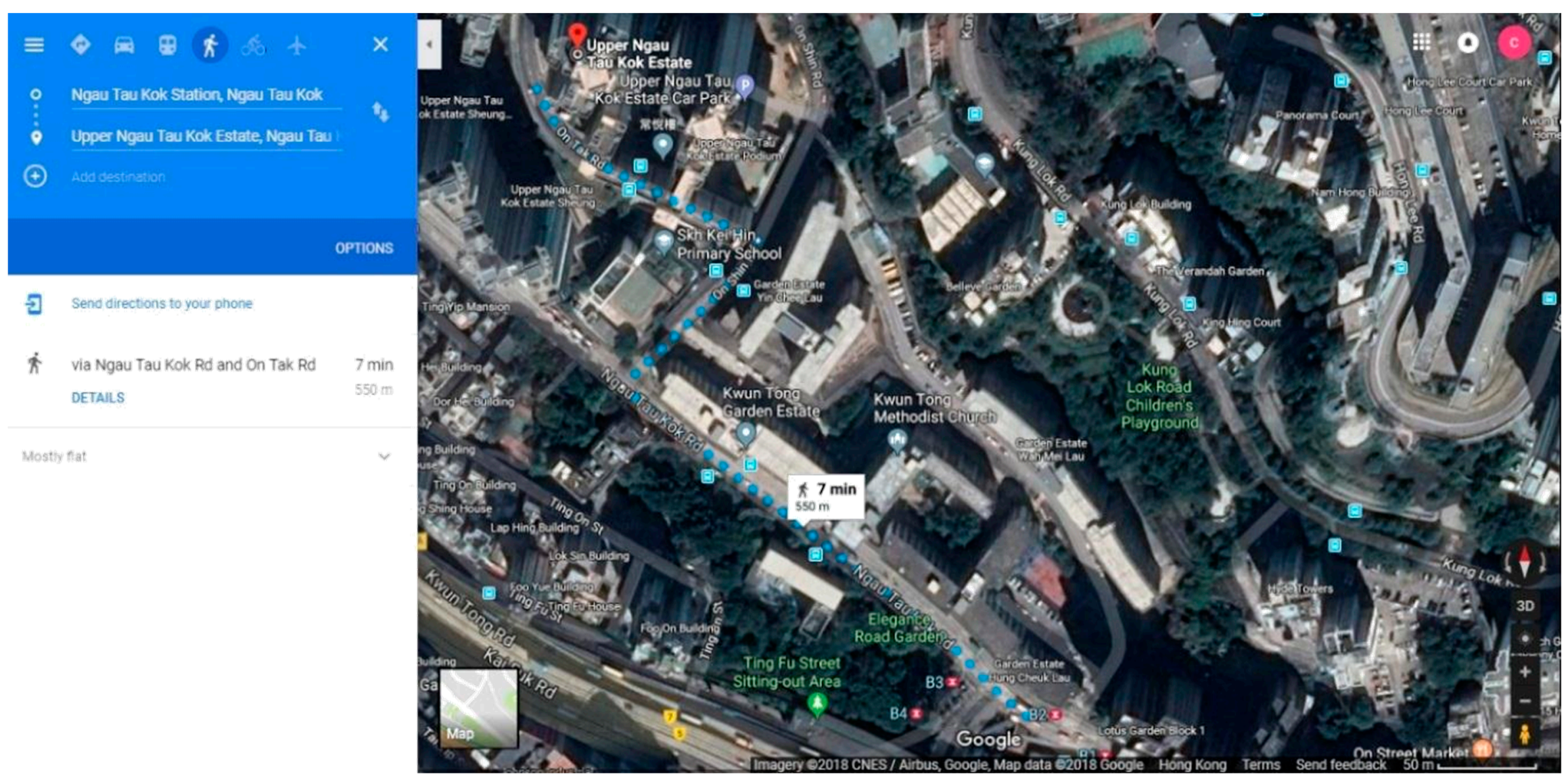

Figure 15. Walking route between Upper Ngau Tau Kok Estate and the Ngau Tau Kok MTR station. 


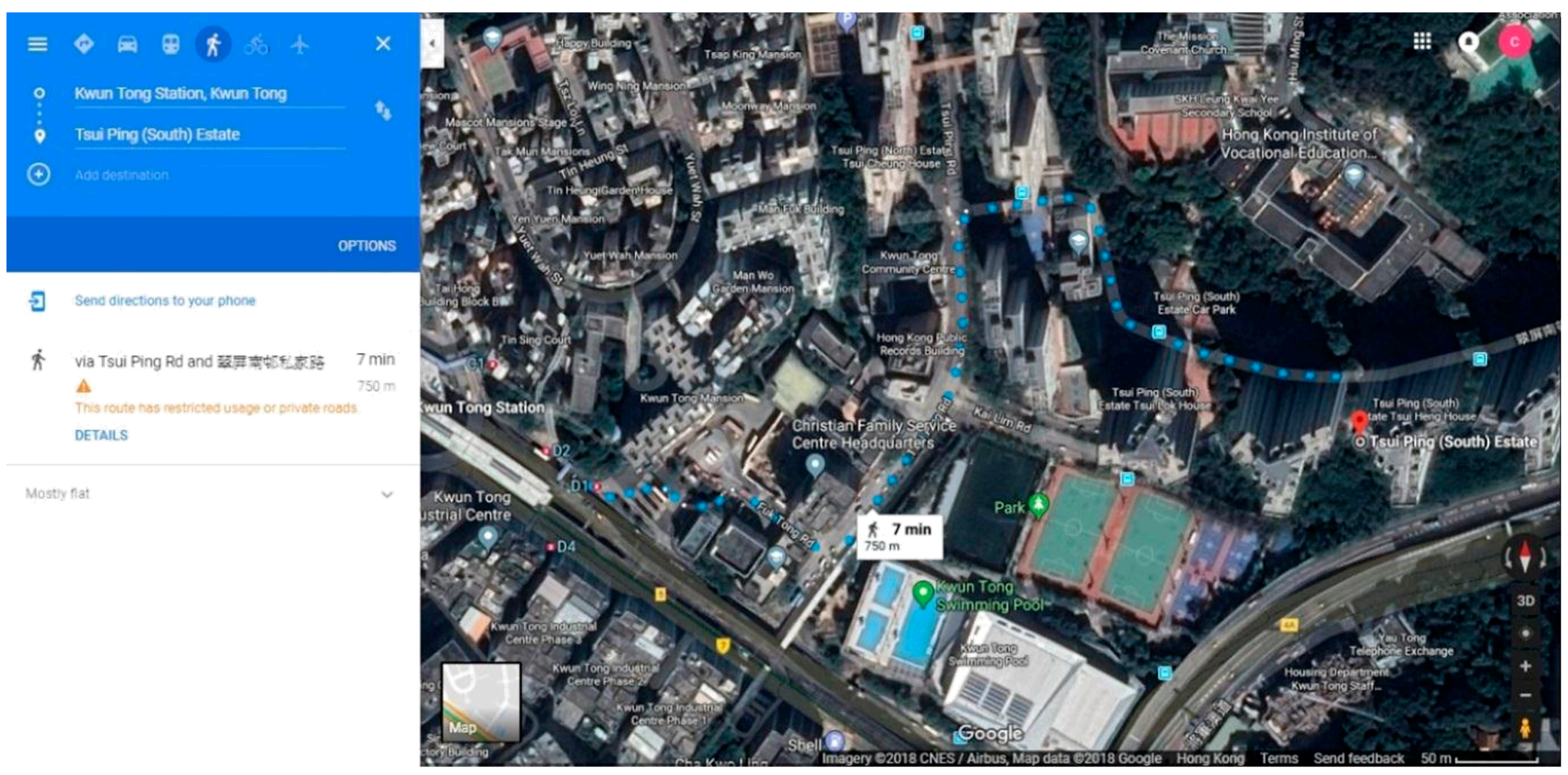

Figure 16. Walking route between Tsui Ping (South) Estate and the Kwun Tong MTR station. 


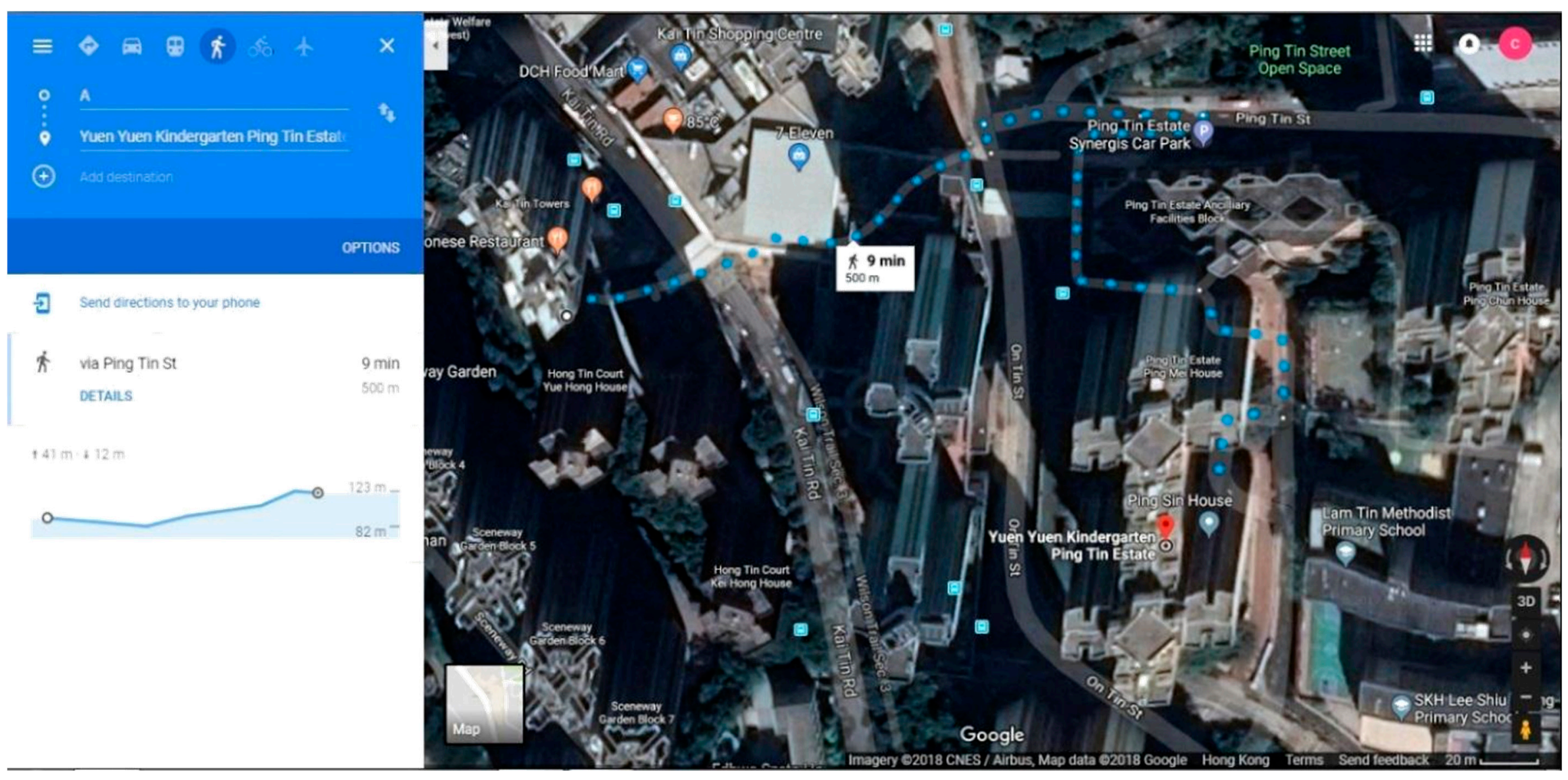

Figure 17. Walking route between Ping Tin Estate and the Lam Tin MTR station. 


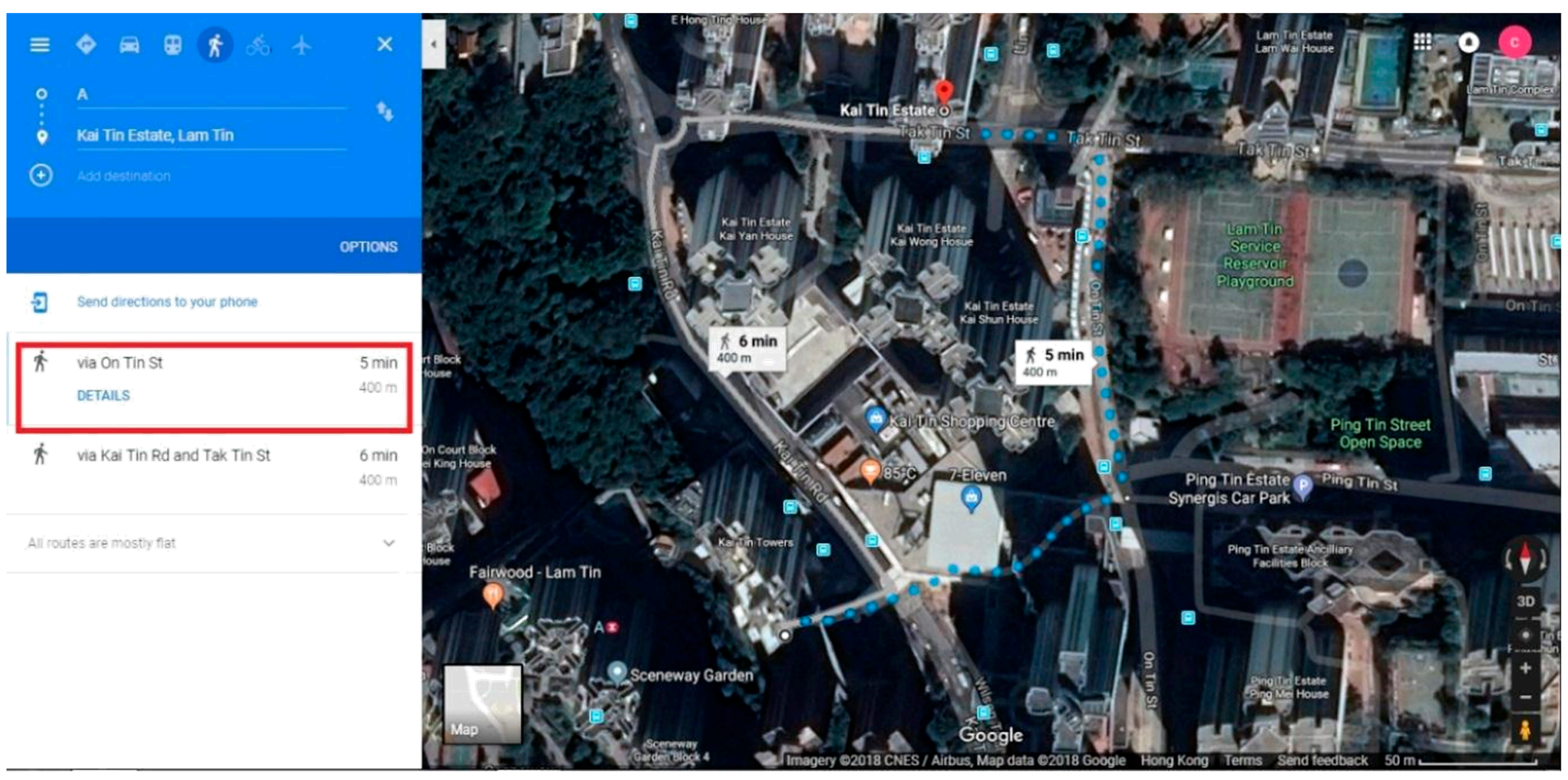

Figure 18. Walking route between Kai Tin Estate and the Lam Tin MTR station. 


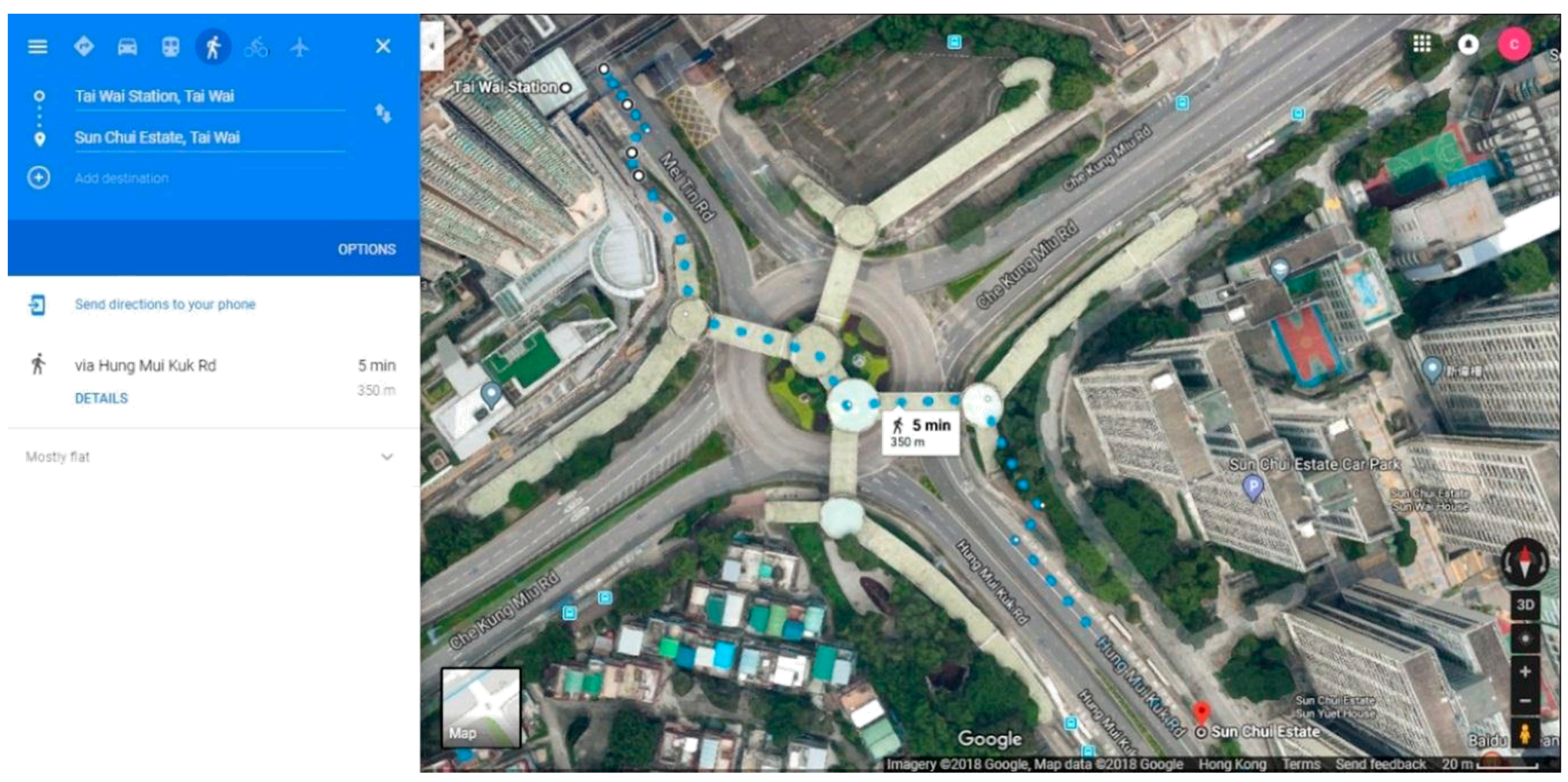

Figure 19. Walking route between Sun Chui Estate and the Tai Wai MTR station. 


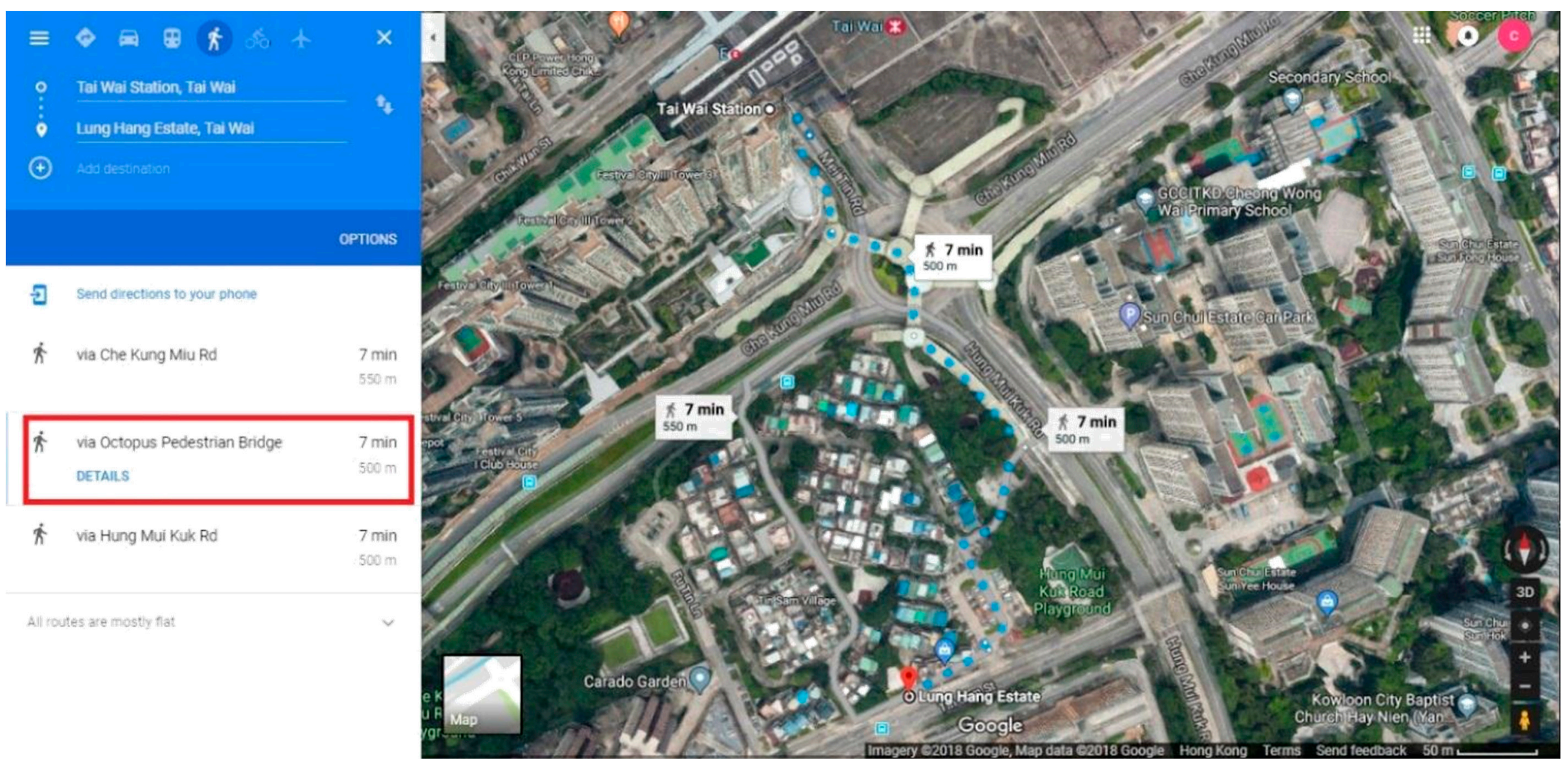

Figure 20. Walking route between Lung Hang Estate and the Tai Wai MTR station. 
Surveys were conducted during the field studies. Three types of pedestrians using the 15 routes were targeted: (1) the elderly; (2) adults; and (3) children. In total, 765 elderly, 657 adult, and 674 children responses were collected for further analysis. Informal interviews were conducted during the one-on-one surveys. To further investigate the 15 routes with ease for different types of pedestrians, the survey aimed to investigate their needs in detail, as well as the convenience of existing facilities, and any possible future implementations for improvement.

\section{Survey Results and Discussions}

Tables 4-6 summarize the survey results for the elderly, adults, and children respectively. In Table 4, it can be seen that most of the elderly had trouble going toward MTR stations on foot, which is evidence that the Hong Kong elderly are facing certain problems associated with deficiencies regarding the existing barrier-free design. It is also evidence that handrails are a necessity for the elderly who face difficulties when walking toward MTR stations from their public rental housing estates. From the survey results, it was found that handrails could help to overcome the difficulties and issues with the central elements of a barrier-free design community. Unexpectedly, most of the elderly were unsure with regards to the adequate provision of handrails, while approximately $35 \%$ of them thought that there was an insufficient number of in handrails. It was concluded that the insufficient provision of handrails potentially leads to a worse barrier-free atmosphere. Thus, an alteration, amendment, or improvement of the existing handrail layout is required.

Table 4. Survey results for the elderly.

\begin{tabular}{lccc}
\hline \multirow{2}{*}{ Questions for the Elderly } & Yes & No & Not Sure \\
\cline { 2 - 4 } & \multicolumn{3}{c}{ (\%) } \\
\hline Do you feel any difficulties when going toward MTR stations on foot? & 63 & 21 & 16 \\
Can handrails reduce the difficulties? & 87 & 4 & 9 \\
Do you think handrail provision is sufficient? & 6 & 35 & 59 \\
Do you think there is a lack of handrails for horizontal pathways? & 48 & 9 & 43 \\
Do you think handrails should be installed on fences? & 53 & 21 & 25 \\
Do you think the existing fences should be replaced by barrier railings? & 8 & 6 & 86 \\
Do you think handrails are provided in an intermittent manner? & 69 & 2 & 29 \\
Do you think continuous handrails could reduce the difficulties of walking? & 62 & 3 & 35 \\
$\begin{array}{l}\text { Do you have any difficulties using handrails due to the handrail system not } \\
\text { being installed on both sides of the pathway? }\end{array}$ & 30 & 10 & 60 \\
$\begin{array}{l}\text { Do you ever have to give up the usage of handrails due to a blockage of the } \\
\text { handrails by any features? }\end{array}$ & 7 & 36 & 57 \\
\hline
\end{tabular}

Table 5. Survey results for adults.

\begin{tabular}{lccc}
\hline & Yes & No & Not Sure \\
\cline { 2 - 4 } Questions for Adults & \multicolumn{3}{c}{ (\%) } \\
\hline $\begin{array}{l}\text { Do you think handrail provision is sufficient? } \\
\text { Do you think handrails are an obstacle to your daily life? }\end{array}$ & 20 & 44 & 36 \\
Have you suffered any injury or damage due to handrails? & 10 & 52 & 38 \\
Do you think handrails are too hard to access due to their height? & 3 & 68 & 29 \\
Do you think handrails are provided in an intermittent manner? & 4 & 5 & 91 \\
Do you think continuous handrails would induce obstacles to your daily life? & 34 & 21 & 27 \\
$\begin{array}{l}\text { Do you think additional handrails installed on horizontal surfaces would be } \\
\text { beneficial (safety, security, lower physical effort) for your daily life? }\end{array}$ & 20 & 27 & 21 \\
$\begin{array}{l}\text { Do you think a handrail system installed on both sides of pathways would be } \\
\text { beneficial (safety, security, lower physical effort) for your daily life? }\end{array}$ & 25 & 17 & 53 \\
$\begin{array}{l}\text { Do you think additional handrails installed on fences would be beneficial } \\
\text { (safety, security, lower physical effort) for your daily life? }\end{array}$ & 16 & 4 & 80 \\
$\begin{array}{l}\text { Do you think the replacement of fences with barrier railings would be } \\
\text { beneficial (safety, security, lower physical effort) for your daily life? }\end{array}$ & 46 & 26 & 28 \\
\hline
\end{tabular}


Table 6. Survey results for children.

\begin{tabular}{lccc}
\hline & Yes & No & Not Sure \\
\cline { 2 - 4 } Questions for Children & \multicolumn{2}{c}{ (\%) } \\
\hline Do you think handrail provision is sufficient? & 44 & 2 & 54 \\
Do you think handrails are an obstacle to your daily life? & 6 & 10 & 84 \\
Have you suffered any injury or damage due to handrails? & 0 & 82 & 18 \\
Do you think handrails are too hard to access due to their height? & 24 & 24 & 52 \\
Do you think handrails are provided in an intermittent manner? & 10 & 2 & 88 \\
Do you think continuous handrails would induce obstacles to your daily life? & 9 & 5 & 86 \\
$\begin{array}{l}\text { Do you think additional handrails installed on horizontal surfaces would be } \\
\text { beneficial (safety, security, lower physical effort) for your daily life? }\end{array}$ & 7 & 17 & 76 \\
$\begin{array}{l}\text { Do you think a handrail system installed on both sides of pathways would be } \\
\text { beneficial (safety, security, lower physical effort) for your daily life? }\end{array}$ & 5 & 34 & 61 \\
$\begin{array}{l}\text { Do you think additional handrails installed on fences would be beneficial } \\
\text { (safety, security, lower physical effort) for your daily life? }\end{array}$ & 28 & 39 & 33 \\
$\begin{array}{l}\text { Do you think the replacement of fences with barrier railings would be } \\
\text { beneficial (safety, security, lower physical effort) for your daily life? }\end{array}$ & 12 & 15 & 73 \\
\hline
\end{tabular}

Nearly half of the elderly believed that there was an insufficient provision of handrails on horizontal pathways. Since there was no mention of handrail provision on horizontal pathways within the guides, this design provision should be considered in the future.

In Table 6 , over $90 \%$ of children were unsure or did not think additional handrails on horizontal surfaces would be a hindrance. A potential reason behind this is probably the minor group of children who enjoy access to additional handrails on horizontal surfaces. On the other hand, $66 \%$ of adults (Table 5) were unsure or did not think additional handrails on horizontal surfaces would be a hindrance.

A large proportion of the elderly found that there was a lack of handrails on horizontal pathways and that they should be installed on fences. Around 33\% of the children were unsure with regards to handrails on both sides of pathways, while $39 \%$ of them did not think that it would be beneficial. This could be due to the possibility of a reduction in space for children. Therefore, two-sided handrails should also be provided optionally in certain children entertainment areas in between the route, for example, between Lower Ngau Tau Kok Estate and the Kowloon Bay MTR station.

Approximately $86 \%$ of the elderly were unsure whether replacing fences with barrier railings was a good idea. The reason for this was probably insufficient knowledge on or experience using barrier railings due to a lack of provision of barrier railings; therefore, the replacement design was not adopted in the guide designed herein. The majority of adults considered that the replacement of fences with barrier railings would be beneficial; however, instead of permanently implementing this idea, optional barrier railings are suggested for designers dependent on local usage and frequency in terms of the environment.

Based on the question "Do you think handrails are provided in intermittent manner?", it is evident that handrails should be installed on a continuous basis in terms of materials, color, size, etc. Evidently, the majority of the children were unsure with regards to the continuous arrangement of handrails, probably due to a lack of use, while $50 \%$ of adults thought that the continuous arrangement of handrails would be beneficial. Therefore, continuous handrails are recommended.

Regarding handrails on both sides of pathways, most respondents were unsure, which indicated a currently sufficient installation of double-sided handrails. However, to alleviate the concerns of those facing obstacles when using handrails, double-sided handrails are still recommended. If no walls are present, then grounded handrails should be used in possible conditions. Over $90 \%$ of respondents were unsure or had no experience of blockage due to handrails. Consequently, in reality, such a realization might have resulted in them choosing another path toward the MTR stations. Therefore, the idea of setting handrails a certain distance away from standing fixtures was eliminated due to the inefficient use of coverage once implemented. 


\section{Major Issues of Handrails}

Based on the survey results and the research team's observations during the field studies, some major issues of handrails were identified, as described below.

\section{A Lack of Handrails on Horizontal Surfaces}

Although there was no guideline for the installation of handrails on horizontal surfaces, there was an obvious problem for the elderly being unable to walk through the entire route (Figure 21).

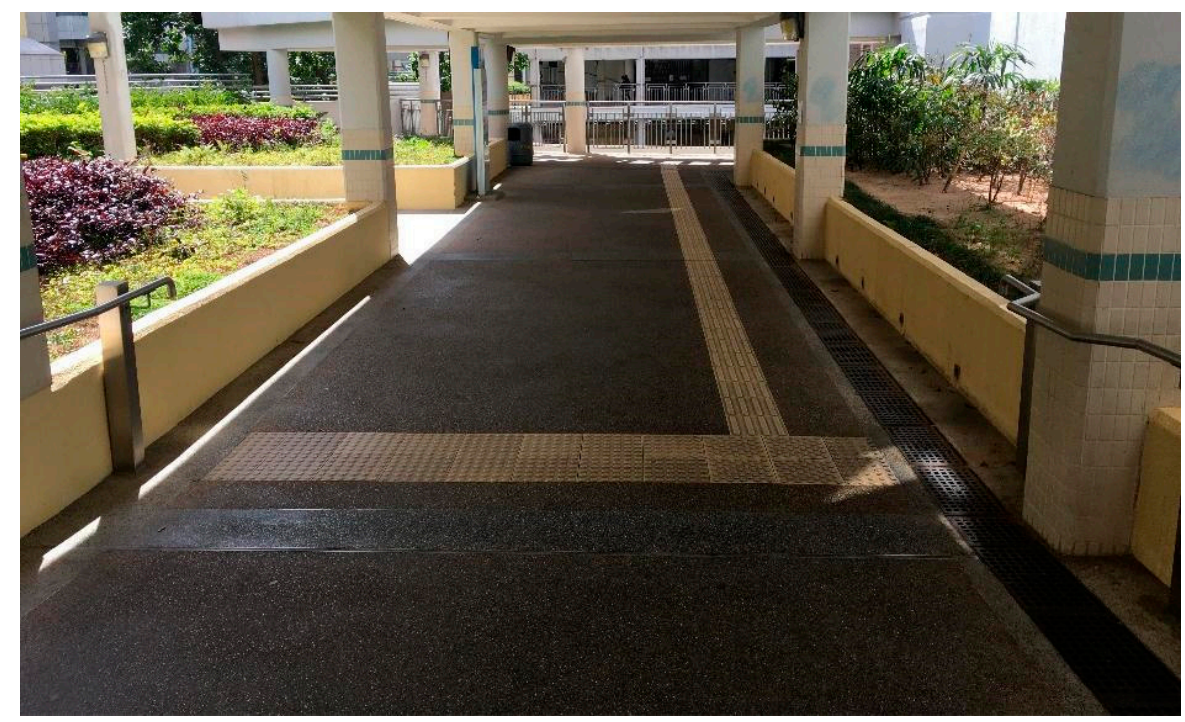

Figure 21. Handrail layout between Lower Ngau Tau Kok Estate and the Ngau Tau Kok Station.

\section{Discontinuity of Handrails}

Although there were some guidelines describing a continuity requirement, it was seldom illustrated. Therefore, in actuality, some handrails were not designed on a continuous basis (Figures 22-24).

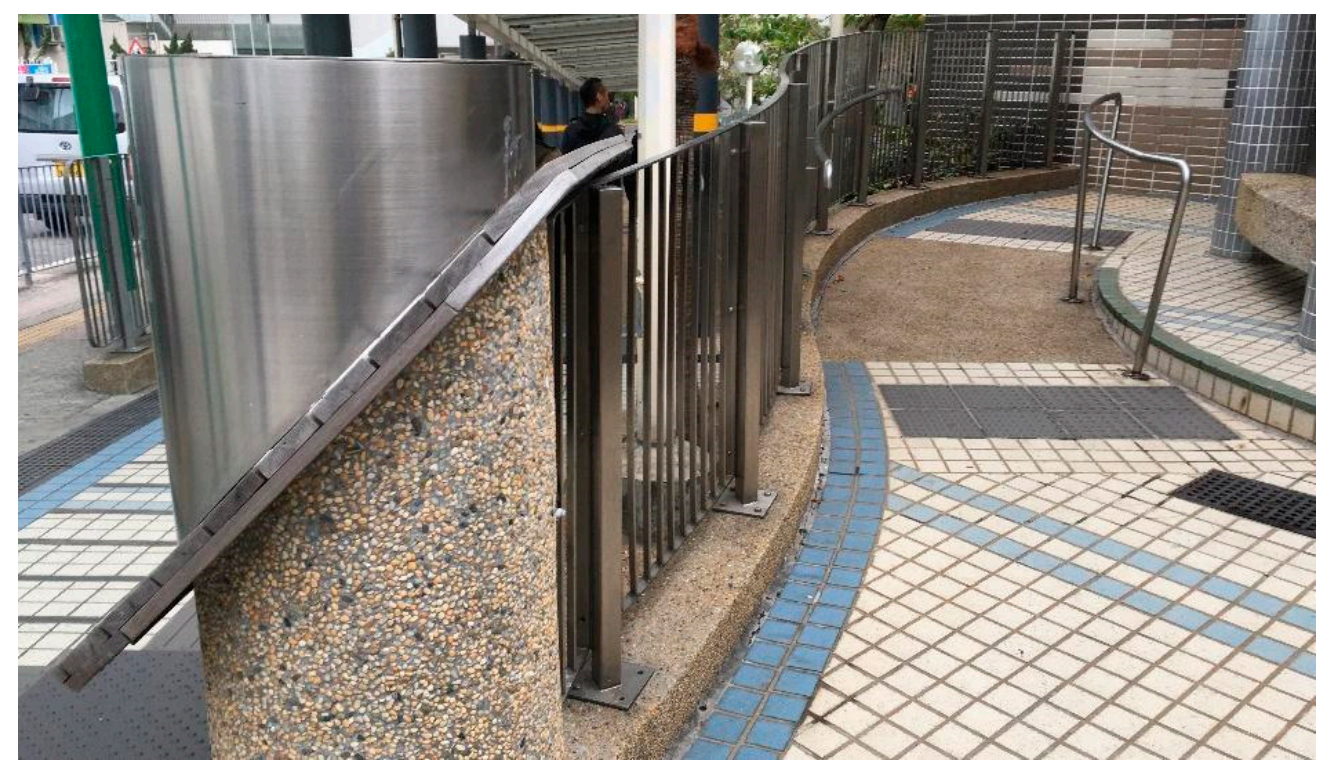

Figure 22. Handrail layout between Shek Kip Mei Estate and the Shek Kip Mei MTR station. 


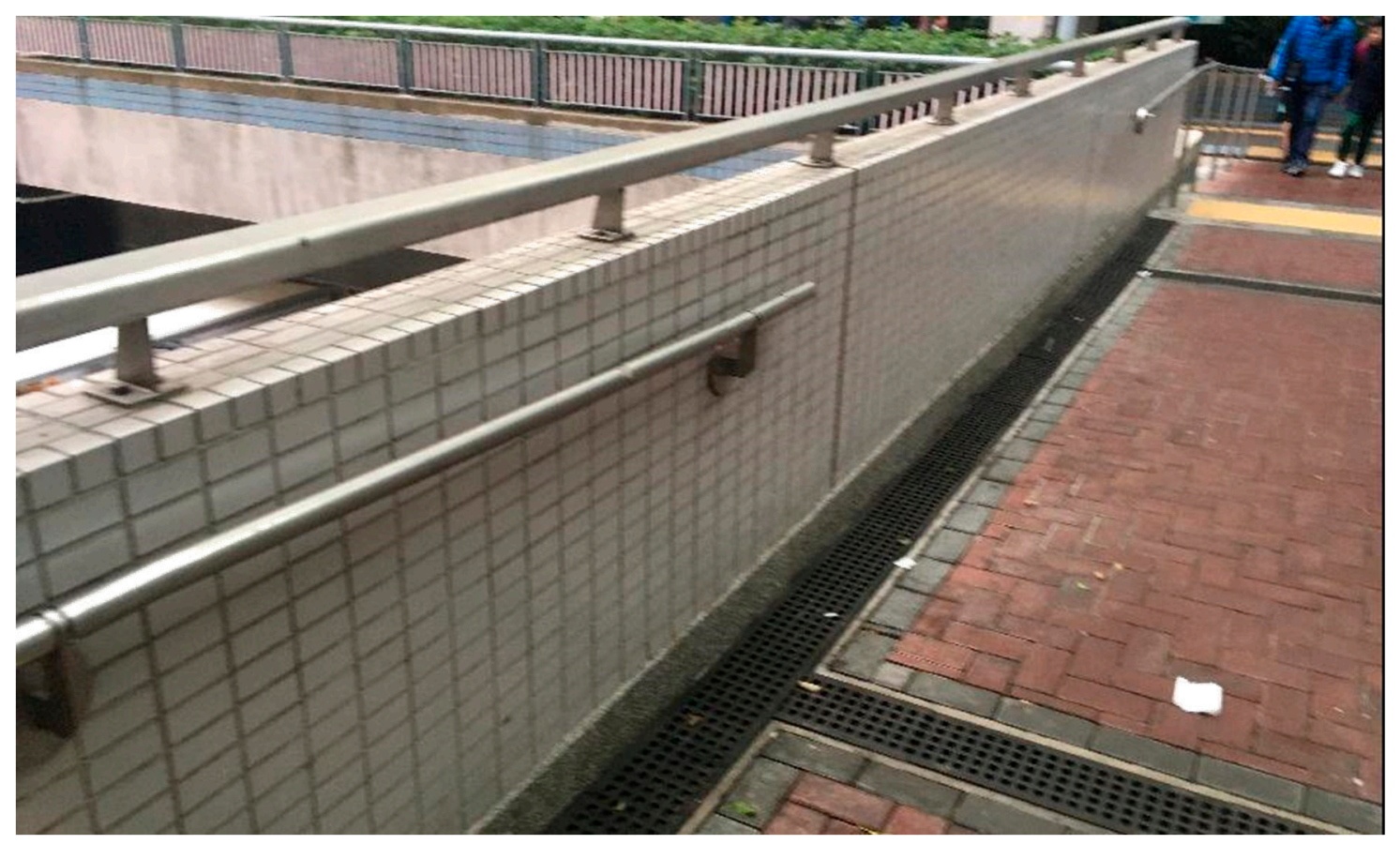

Figure 23. Handrail layout between Kai Tin Estate and the Lam Tin MTR station.

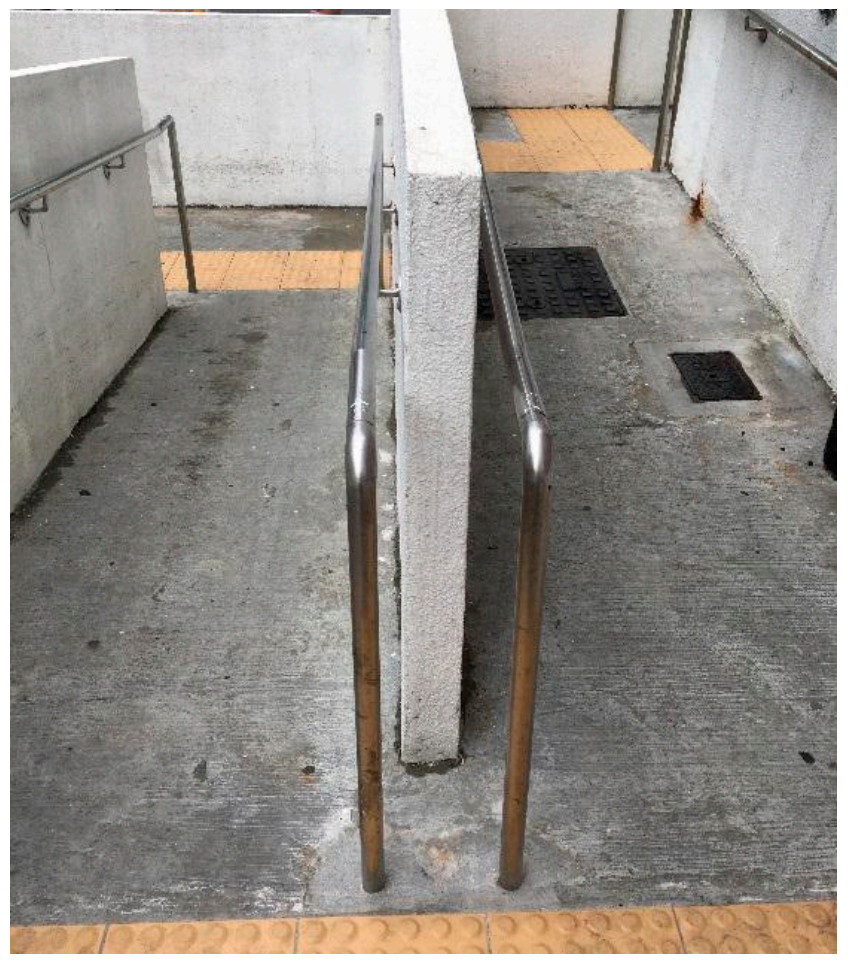

Figure 24. Handrail layout between Nam Shan Estate and the Shek Kip Mei MTR station.

\section{$\underline{\text { Handrails Were Not Installed on Both Sides }}$}

To allow equitability in use, handrails on both sides of a pathway are necessary. However, this layout was ignored in some routes, which might create inconvenience for users with paralysis, for example (Figures 25 and 26). 


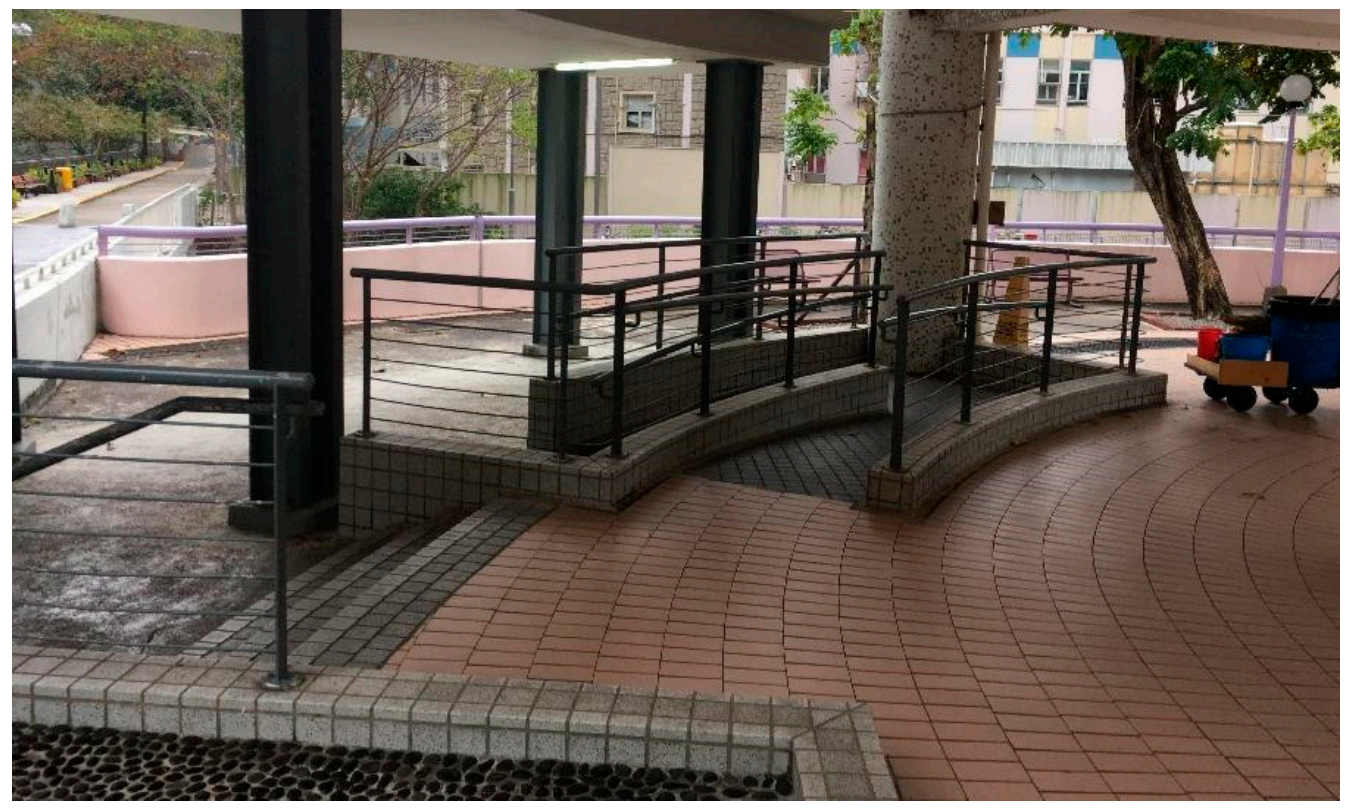

Figure 25. Handrail layout between Wang Tau Ham Estate and the Lok Fu MTR station.

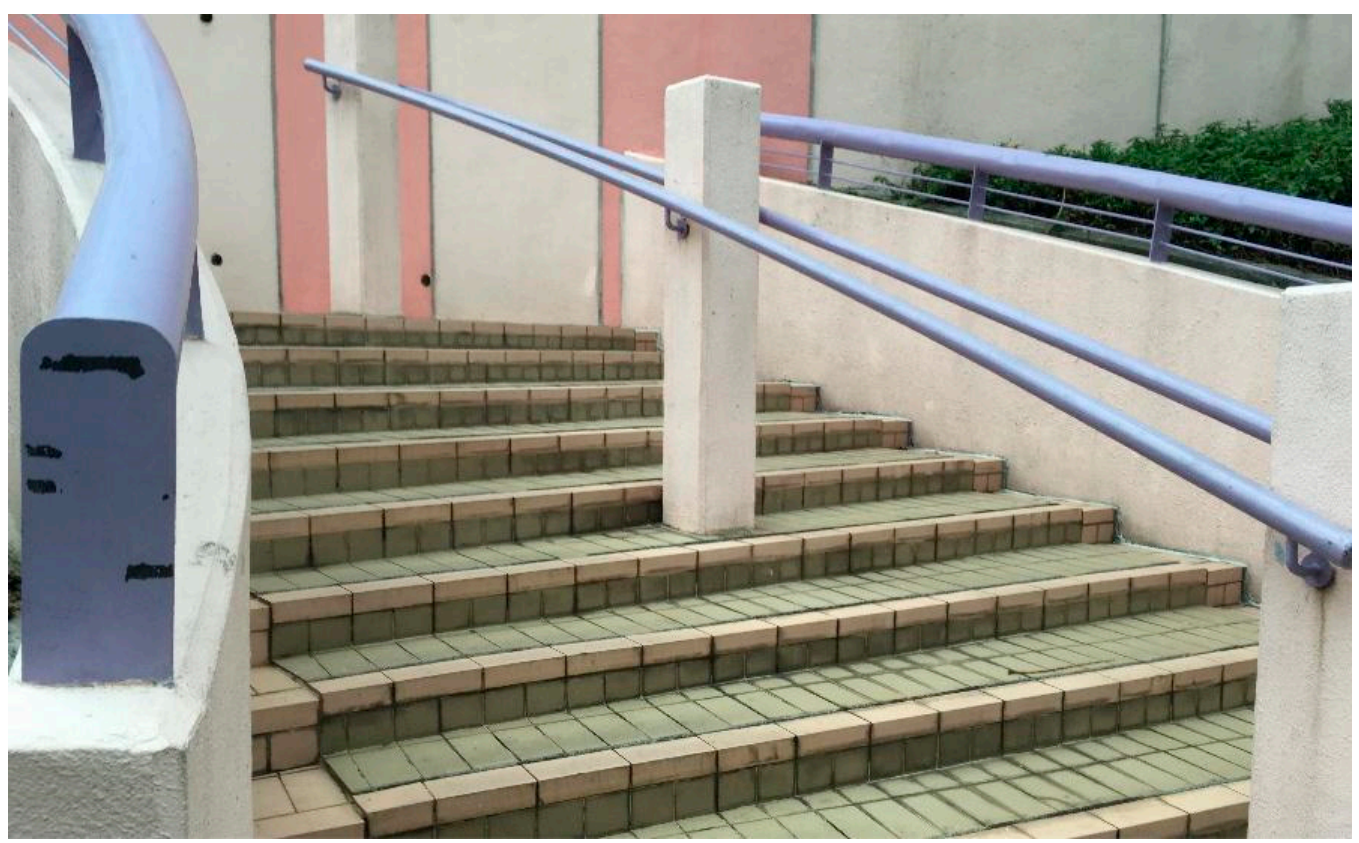

Figure 26. Handrail layout between Wang Tau Ham Estate and the Lok Fu MTR station.

\section{Undesirable Installation Location}

Handrails were not installed in appropriate locations at times, i.e., installed at the top side of curbs instead of sideways (Figure 27). 


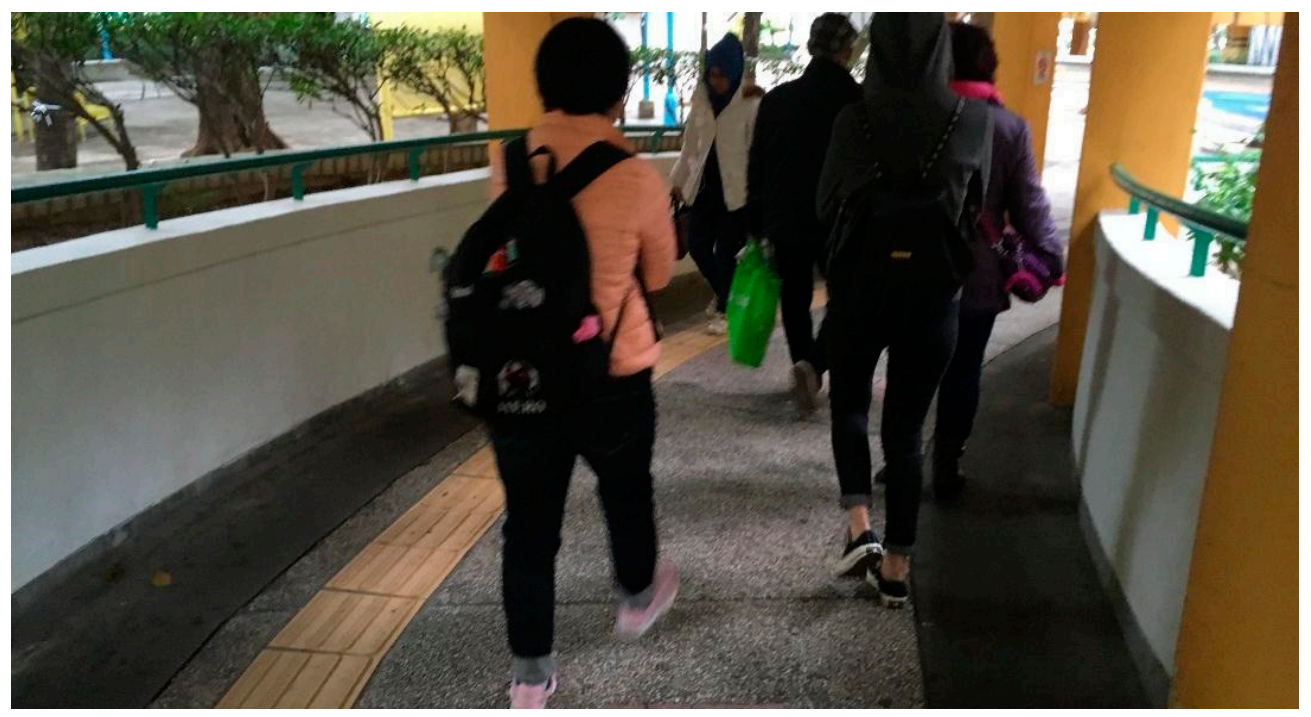

Figure 27. Handrail layout between Lower Wong Tai Sin Estate and the Wong Tai Sin MTR Station.

\section{Handrails Were Not Installed on Fences}

Handrails were not installed on some fences which allows handrail installation. To promote a barrier-free design of handrails, fences should be installed with handrails in some practical situations (Figure 28).

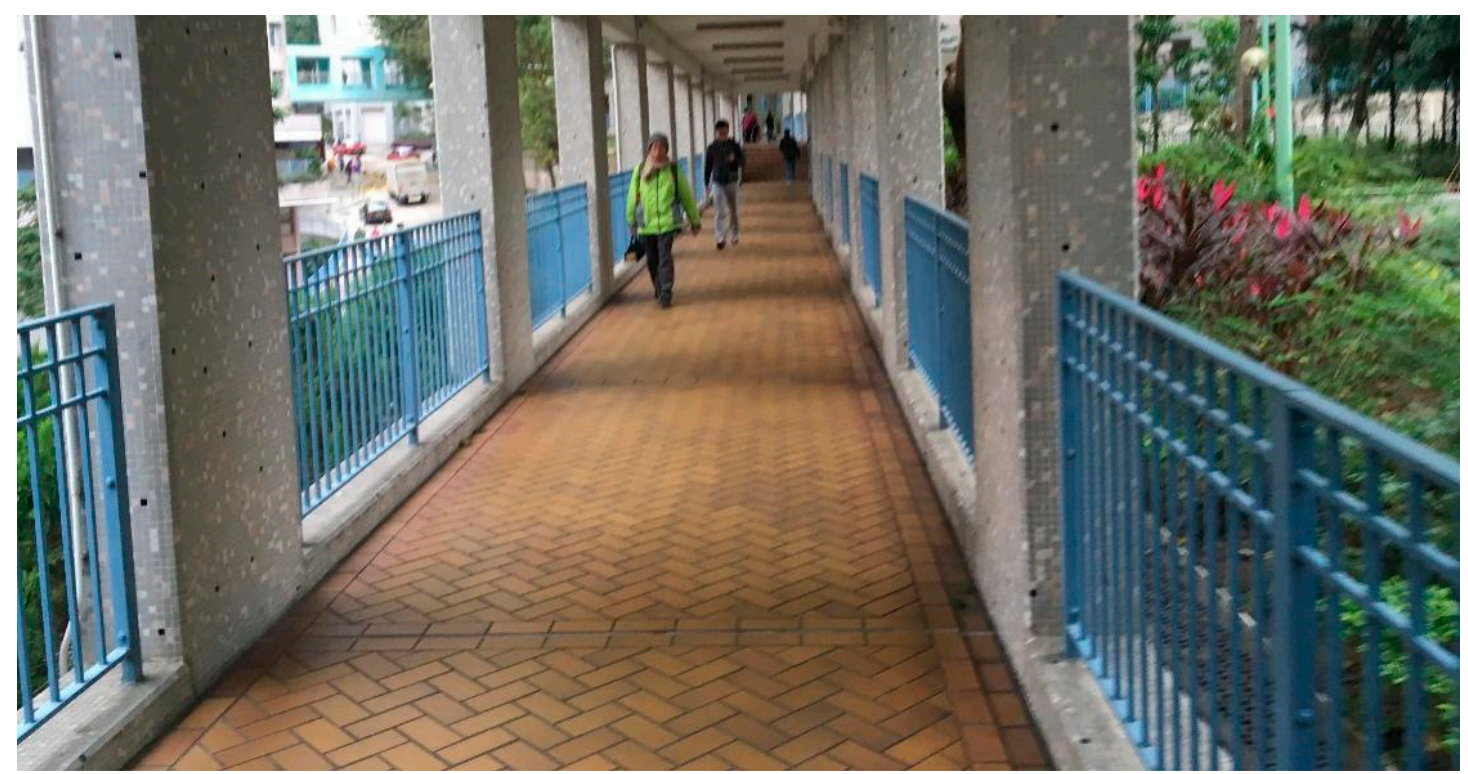

Figure 28. Handrail layout between Fung Tak Estate and the Diamond Hill MTR Station.

\section{Blockage of Handrails}

Some handrails were blocked by existing features, which might create a barrier to users or even invalidate the function of handrails, potentially leading to Inconvenience upon use (Figure 29). 


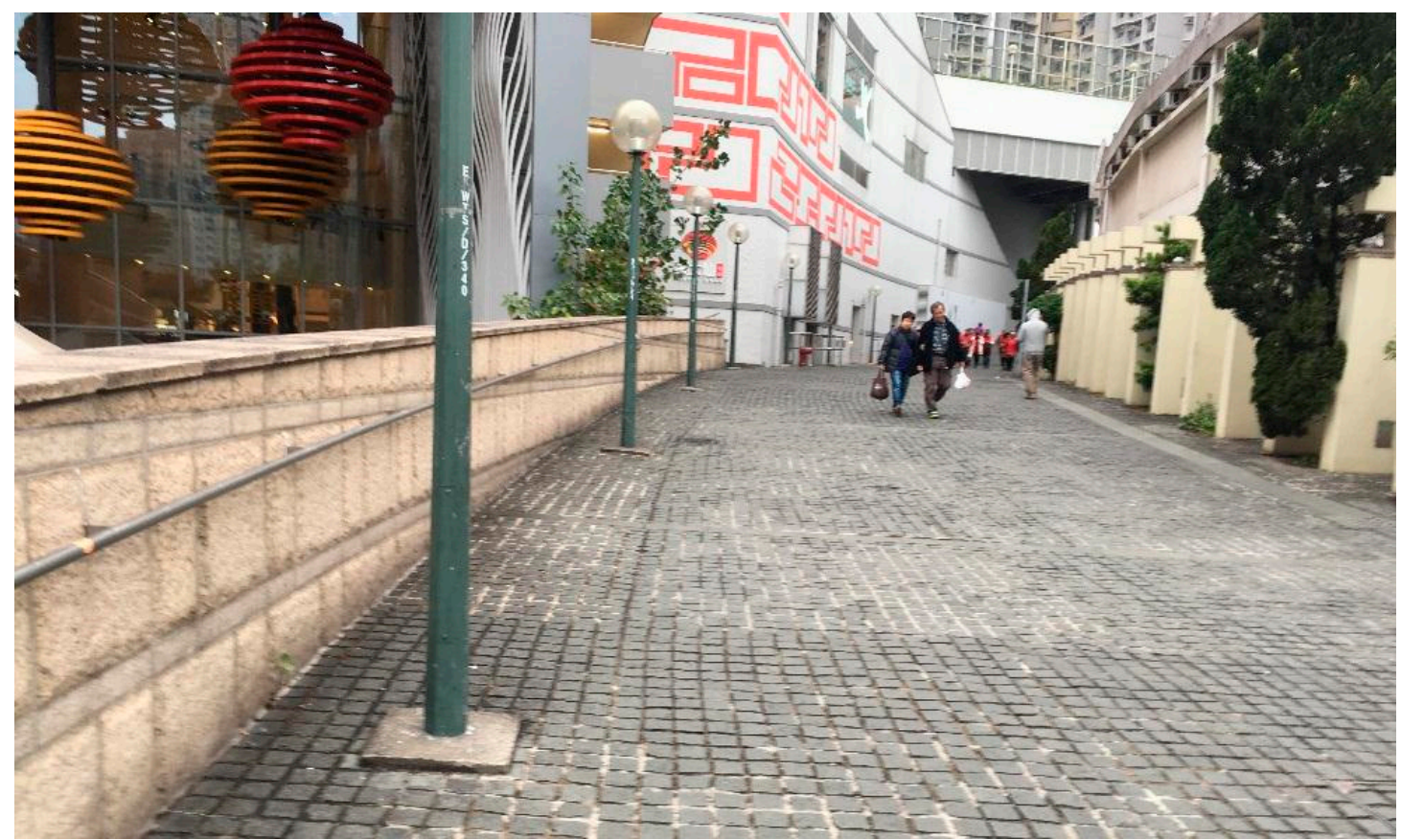

Figure 29. Handrail layout between Upper Wong Tai Sin Estate and the Wong Tai Sin MTR Station.

\section{Good Practices with Handrails}

Apart from the above issues with handrails, there were some unexpected layouts observed from field studies which might be beneficial for the elderly.

\section{Handrails Installed on Bus Stop}

The idea of this design could improve travel for the elderly and even give support to the elderly, especially on rainy days (Figure 30).

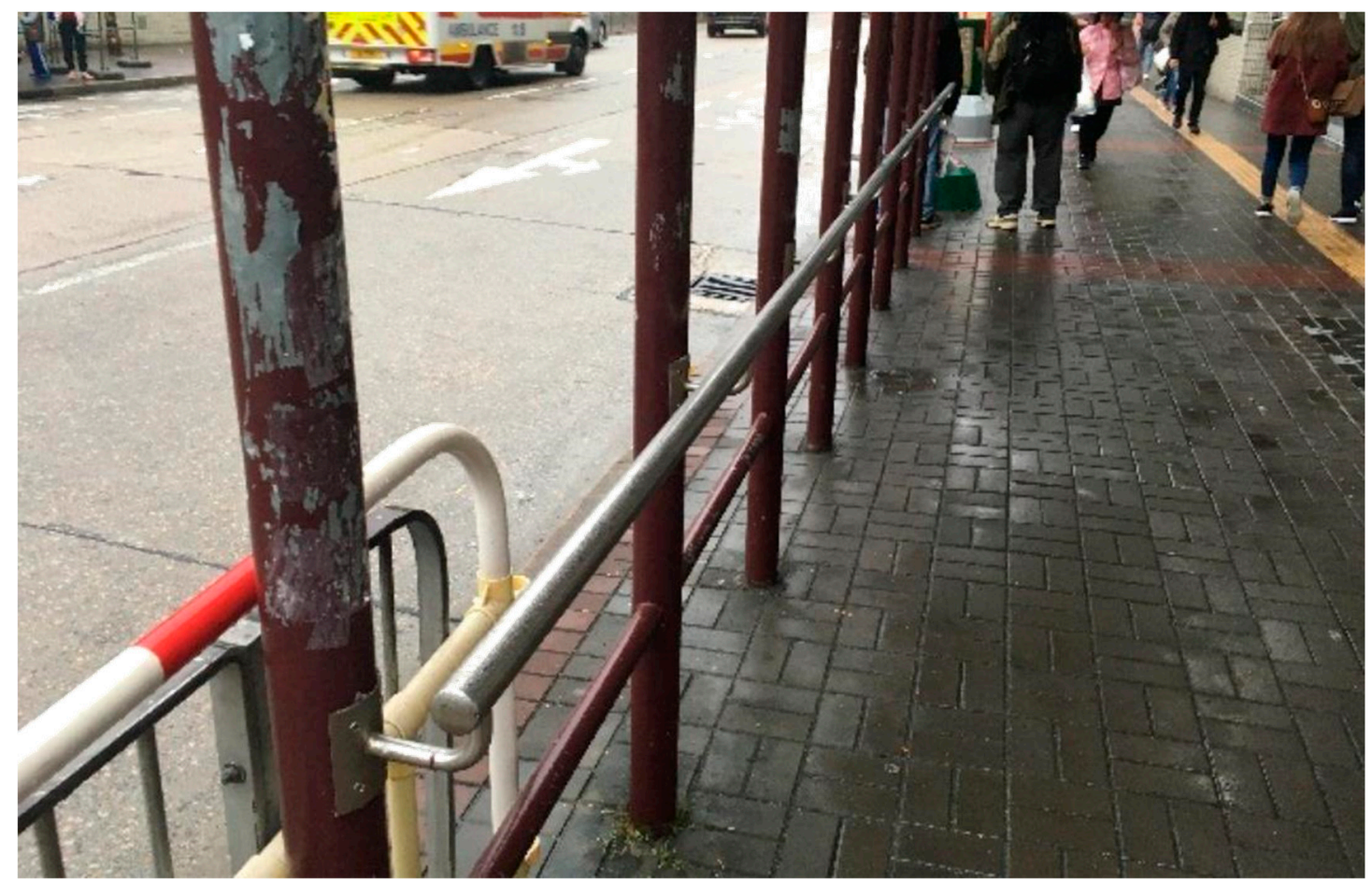

Figure 30. Handrail layout on bus stop between Tsui Ping (South) Estate and the Kwun Tong MTR station. 


\section{Handrails Installed on Lower Curb}

The idea of this design, whereby handrails are provided on lower curbs, can be utilized on some routes with small pathways (Figure 31).

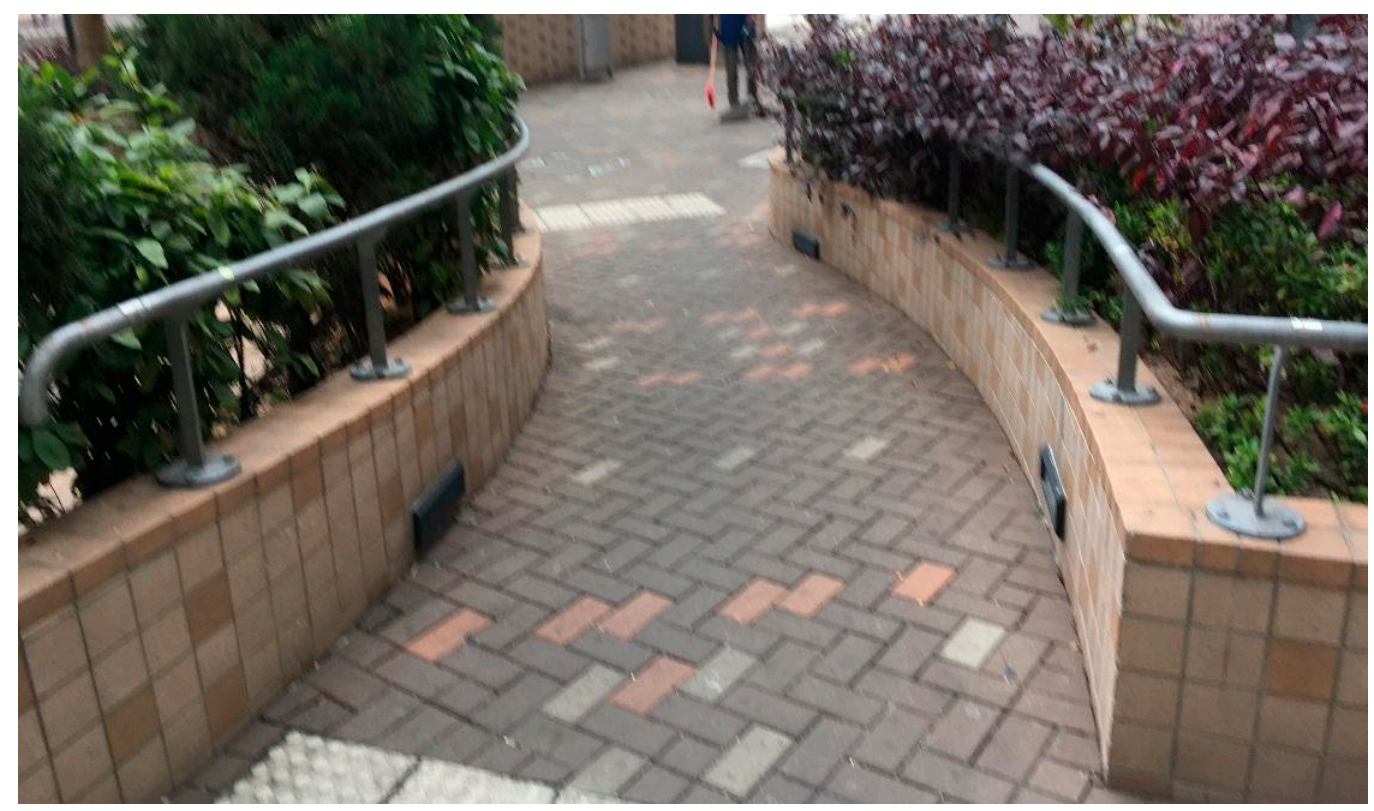

Figure 31. Handrail layout on lower curb near Shek Kip Mei.

\section{Handrails Installed at the Bottom of Escalators}

The idea of this design, whereby handrails are used to support the elderly, can be implemented in routes featuring escalators (Figure 32).

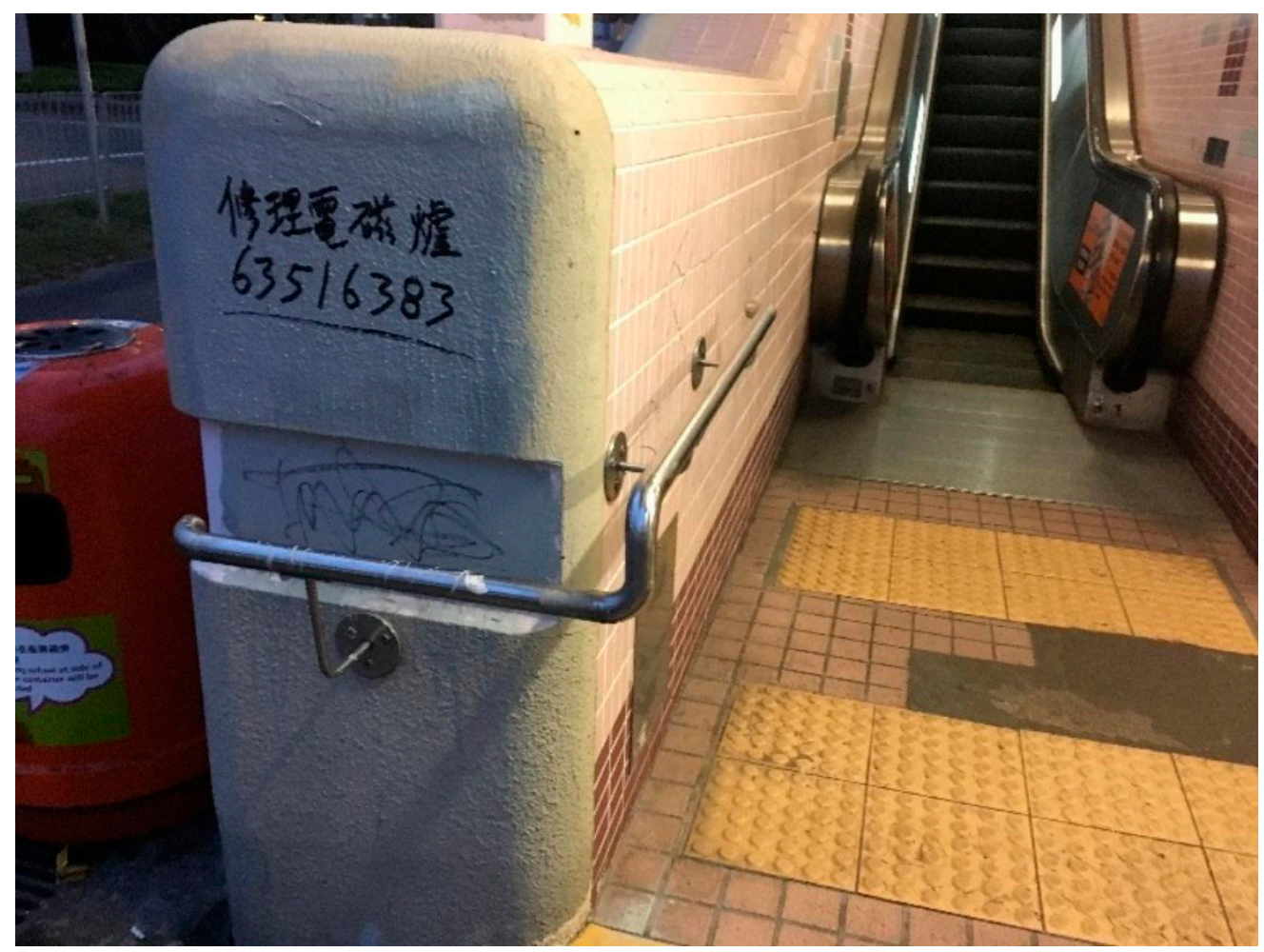

Figure 32. Handrail layout before an escalator between Sun Chui Estate and the Tai Wai MTR station. 


\section{Development of the Universal Guide for Handrails}

Based on the survey results, field studies, and interviews with pedestrians, the Universal Guide for Handrails was developed, and is provided in the Supplementary Materials. There are two sections in the Universal Guide. The first section features design requirements, including height, material, cross-section, distance from wall, load resistance, shape, extension, ramps, gripping surface, removable handrails, and safety dots. There is also an advanced design developed for the Universal Guide called "Elderlysteady", which is a material design for detecting loading and speed for the adjustment of moving rate, featuring an indicator light, and a continuous design. In addition, Section B suggests layout requirements for the Universal Guide, including fencing, horizontal surfaces, low curbs, double-sided handrails, bus stops, and escalators.

This guide aimed to evaluate the needs of the elderly (over 59 years of age) living in public rental housing flats, based on additional input from children and adults, thereby achieving the idea of universal design. Detailed requirements for design and layout are provided and recommended. This guide was developed based on a Hong Kong empirical study; however, it should also be suitable for other densely populated cities and countries. This guide can provide insight for architects of handrails, with focus on the needs of the elderly.

\section{Conclusions}

This paper developed a universal design guide for handrails focusing on the needs of the elderly. Surveys, 15 field studies, and interviews were conducted to investigate the major issues concerning handrails, which were then used to develop a universal guide for handrails. Providing additional recommendations to designers, an advanced section of the guide features a design called "ElderlySteady", which was developed in the contexts of technology, environment, and self-support. Based on the results, most problems with existing handrails could be found within the community. Most children or adults were unsure with regards to the feasibility of the current design, suggesting that the existing barrier-free design exhibited some elements of the universal design guide, but not to a satisfactory level. During the design process, some ideas from adults were sacrificed so as to achieve more universal acceptance and flexibility for all age groups.

Supplementary Materials: The following Universal Guide for Handrails is available online at http:/ /www.mdpi. com/2071-1050/10/11/4233/s1.

Author Contributions: V.W.Y.T. and I.W.H.F. have contributed for the overall development of the research. Y.T.T. has contributed as research method and L.C. has collected the survey and analysis.

Funding: This research received no external funding.

Conflicts of Interest: The authors declare no conflicts of interest.

\section{References}

1. King, S.L.; Vanicek, N.; O'Brien, T.D. Joint moment strategies during stair descent in patients with peripheral arterial disease and intermittent claudication. Gait Posture 2018, 62, 359-365. [CrossRef] [PubMed]

2. Moniz-Pereira, V.; Kepple, T.M.; Cabral, S.; Joao, F.; Veloso, A.P. Joint moments' contributions to vertically accelerate the center of mass during stair ambulation in the elderly: An induced acceleration approach. J. Biomech. 2018, 79, 105-111. [CrossRef] [PubMed]

3. World Health Organization. Global Age-Friendly Cities: A Guide; World Health Organization: Geneva, Switzerland, 2007.

4. Komisar, V.; Nirmalanathan, K.; Novak, A.C. Influence of handrail height and fall direction on center of mass control and the physical demands of reach-to-grasp balance recovery reactions. Gait Posture 2018, 60, 209-216. [CrossRef] [PubMed]

5. King, S.L.; Underdown, T.; Reeves, N.D.; Baltzopoulous, V.; Maganaris, C.N. Alternate stair descent strategies for reducing joint moment demands in older individuals. J. Biomech. 2018, 78, 126-133. [CrossRef] [PubMed] 
6. Elhadi, M.M.O.; Ma, C.Z.H.; Lam, W.K.; Lee, C.C. Biomechanical approach in facilitating long-distance walking of elderly people using footwear modifications. Gait Posture 2018, 64, 101-107. [CrossRef] [PubMed]

7. Xiang, Z.R.; Zhi, J.Y.; Dong, S.Y.; Li, R.; He, S.J. The impacts of ergonomics/human factors of wheelchair/user combinations on effective barrier-free environments design: A case study of the Chinese universal rail coach layout. Int. J. Ind. Ergon. 2018, 67, 229-241. [CrossRef]

8. Dusenberry, D.O.; Simpson, H.; DelloRusso, S.J. Effect of handrail shape on graspability. Appl. Ergon. 2009, 40, 657-669. [CrossRef] [PubMed]

9. Department for the Aging-New York City. Aging in Place Guide for Building Owners: Recommended Age-Friendly Residential Building Upgrades; Department for the Aging-New York City: New York City, NY, USA, 2017.

10. Buildings Department. Design Manual_Barrier Free Access; Buildings Department, Hong Kong Government: Hong Kong, China, 2008.

11. Architectural Services Department. Universal Accessibility-Best Practices and Guidelines; Architectural Services Department, Hong Kong Government: Hong Kong, China, 2018.

12. Mass Transit Railway (MTR). Caring for Our Customers with Special Needs Booklet; Mass Transit Railway: Hong Kong, China, 2018.

13. Isabella, S.; Rahel, Z. Basicas Barrer-Free Planning; Birkhauser Verlag: Basel, Switzerland, 2017.

14. Yanko Design. Safety Dot Handrail. Available online: http://www.yankodesign.com/2011/03/28/ handrails-that-speak / (accessed on 8 October 2011).

15. Hong Kong Green Building Council. HSMC Jockey Club Residential Colleges; Hong Kong Green Building Council: Hong Kong, China, 2018.

16. Hong Kong Green Building Council. BEAM Plus New Building; Building Environmental Assessment Method (BEAM), Hong Kong Green Building Council: Hong Kong, China, 2012.

17. Barker, P.; Barrick, J.; Wilson, R. Building Sight: A Handbook of Building and Interior Design Solutions to Include the Needs of Visually Impaired People; Amer Foundation for the Blind, Better World Books Ltd.: Dunfermline, UK, 1995.

18. Naoto, T. Fukushi No MACHI Zukuri Keyword Jiten Universal Shakai No Kankyo Design; CDJapan: Tokyo, Japan, 2004.

19. National Disability Authority. The 7 Principles of Universal Design; Centre for Excellence in Universal Design, National Disability Authority: Dublin, Ireland, 2018.

20. Unversal Design Style. ADA Focus: Stairways and Handrails. 2012. Available online: http://www. universaldesignstyle.com/ada-focus-stairways-and-handrails/ (accessed on 16 November 2018). 